\title{
NEIGHBORHOOD INFORMATION EXCHANGE AND VOTER PARTICIPATION: AN EXPERIMENTAL STUDY*
}

by

\author{
Jens Großer ${ }^{\mathrm{i}, \mathrm{ii}}$ \\ Arthur Schram ${ }^{\mathrm{i}}$
}

\begin{abstract}
We study the effect of social embeddedness on voter turnout by investigating the role of information about other voters' decisions. We do so in a participation game, where some voters ('receivers') are told about some other voters' ('senders') turnout decision at a first stage of the game. Cases are distinguished where the voters support the same or different candidates or where they are uncertain about each other's preferences. Our experimental results show that such information matters. Participation is much higher when information is exchanged than when it is not. Senders strategically try to use their first mover position and some receivers respond to this.
\end{abstract}

this version: May 2004

\footnotetext{
${ }^{\mathrm{i}}$ Center for Research in Experimental Economics and political Decision making, University of Amsterdam; Roeterstraat 11, 1018 WB Amsterdam, the Netherlands.

ii Department of Economics, University of Cologne; Albertus-Magnus-Platz, 50923 Cologne, Germany.

email: J.W.Grosser@uva.nl; Schram@uva.nl
}

\footnotetext{
*We would like to thank Gary Bornstein, Klarita Gërxhani, and three anonymous referees for helpful comments.
} 


\section{INTRODUCTION}

The 'voter paradox' of why substantial portions of large electorates turn out to vote has puzzled economists since Downs (1957). In the Downsian framework, the probability of being pivotal in large-scale elections is negligible and, therefore, expected revenues from casting a vote fall short of the costs. Many theoretical and empirical papers have been published trying to explain the paradox, but not until the nineteen-eighties did rational choice models start to appear that show that turning out to vote might be rational in an instrumental sense (see Ledyard 1984, or Schram 1991, and the references given there).

Palfrey and Rosenthal (1983) model the turnout decision as a participation game and study it game-theoretically. In this game, there are two or more teams. Everyone has to make a private decision on whether or not to 'participate' in an action, where participation is costly. Participation is beneficial to every member in one's own team and harmful to members of other teams. The team with the higher number of 'participants' gets the (higher) reward. Palfrey and Rosenthal show that in some cases Nash equilibria with sizeable levels of participation exist. However, when the game allows for substantial uncertainty about voters' preferences and costs, equilibria with high participation generally disappear (Palfrey and Rosenthal, 1985). ${ }^{1}$

The participation game simultaneously combines two kinds of conflict: a betweengroup conflict for the higher reward, and a within-group conflict, where each group member has an incentive to free ride on costly participation by other members of the own group. For any given number of players in the other group choosing to participate, the resulting game in the own group boils down to a voluntary contribution mechanism with a step-level public good (e.g., Offerman et al., 1996).

The experimental literature on participation games is still quite limited. Bornstein (1992) was the first to use experiments to study participation in small groups. Schram and Sonnemans (1996a,b) vary group size and compare elections of proportional representation to winner-takes-all elections. Hsu and Sung (2002) investigate participation for equally sized groups in electorates with up to 70 voters. Cason and Mui

\footnotetext{
${ }^{1}$ For specific cases, Börges (2004) and Goeree and Großer (2003) show the existence of a unique equilibrium with positive turnout for some range of parameters under preference uncertainty.
} 
(2003) use the participation game to model reforms and study the impact of payoff uncertainty and varying costs. Finally, Großer et al. (2004) study the effect of preference uncertainty and differences between allied and floating voters. In all of these studies, relatively high rates of participation are found, albeit that lower turnout is observed than in most general elections around the world. Moreover, a typical result in these studies is that the standard Nash equilibria find little support. However, Goeree and Holt (forthcoming) show that a logit equilibrium can account for the Schram and Sonnemans data and Cason and Mui show the same for their own data.

In this paper, we focus on a voter's social environment. An important element of this environment is the information exchanged within it. Here, we explore this exchange of information in an attempt to take the study of voter turnout one step further, whilst maintaining the participation game framework. We do so by giving voters information about the turnout decision of some other voter in their surrounding. This is inspired by the idea that it is quite natural for interaction to take place before and during elections amongst individuals in small social environments or neighborhoods (e.g., a family or working place). Of course, this interaction can be very complex and take on a variety of forms. We are interested in the exchange of information between voters about the candidates they support, and especially about their decision on whether or not to vote. To the best of our knowledge, there has been no thorough analysis to date of how such 'neighborhood information exchange (NIE)' may influence voter participation. We extend the participation game to include NIE and study this game both theoretically and experimentally.

In our model, we focus on neighborhoods that consist of two voters only. ${ }^{2}$ Information exchange between these voters has two dimensions. First, neighbors know whether they support the same or opposing candidates (or that they are uncertain about each other's preferences). Second, one of them can observe whether her neighbor-voter has cast a vote or not. For this, we distinguish between voters who send information and

\footnotetext{
${ }^{2}$ A restriction to two-person neighborhoods is an obvious limitation. However, we are interested in the effect of information per se, and for this, it suffices to focus on the simplest case. Moreover, we shall show that the effect is large, even for the two-person neighborhoods. Bigger and overlapping neighborhoods are an interesting topic for future research.
} 
those who receive it. ${ }^{3}$ This allows us to explicitly study the influence on participation in both roles. The (endogenous) content of information in our setting is the sender's decision whether or not to vote, which is observed by her receiver-neighbor.

In our NIE participation game decisions are made in two stages. There are two (equally sized) groups of players, or voters, and within each group an equal number of senders and receivers of information is distinguished. At stage 1, each sender decides whether to participate or abstain. Each sender knows that (only) her receiver-neighbor will observe this decision. If the sender participates, she does not take part in stage 2. If she abstains, she again decides on participating or abstaining at stage 2, but this time she knows that this decision will not be observed. At stage 2, receivers decide whether or not to participate, knowing their sender-neighbor's stage 1 decision. Note that neither senders nor receivers observe others' stage 2 decisions. The outcome of the game is determined by counting all stage 1 and 2 participation in the two groups, with the higher reward going to the members of the group with the highest participation (with a coin toss deciding in case of a tie).

Though neighborhood information exchange has not been studied in a participation game before, various studies of voting contain elements that are relevant for our set-up. Of special interest are results that relate to the influence on voter participation of (i) social embeddedness and communication and (ii) procedures that combine simultaneous and sequential voting.

We start with a brief discussion of some of the literature concerning the first of these two areas. Putnam et al. (1993) argue that there is an important link between a society's social capital and the level of voter turnout at its elections. Carlson (1999) provides empirical support. One interesting aspect of social embeddedness is whether interaction takes place between allies or adversaries. Schram and van Winden (1991) argue that social pressure and examples set by group leaders play an important role in a voter's deci-

\footnotetext{
${ }^{3}$ Notice the difference between our setup and standard models of information cascades and herding in economic (e.g., Banerjee, 1992; Bikhchandani et al., 1992) and social choice (e.g., Fey, 1996; Wit, 1997) environments. There, everybody is both sender and receiver, except for the first and the last player. In addition, contrary to the participation game, there is a common interest among players in these models. However, Dekel and Piccione (2000) present a sequential voting model that allows for endogenous timing of decisions and for both common and private values. We will briefly discuss this paper, below.
} 
sion. Moreover, there is evidence from empirical and simulation studies that segregation increases voter participation (e.g., Butler and Stokes 1974; Ragin 1986; Takács 2001, 2002). Communication is an important aspect of social embeddedness. Schram and Sonnemans (1996b) show that both group identity and within-group communication increase turnout in experimental participation games. Goren and Bornstein (2000) find the same; in addition, they also show that groups use the opportunity of communication to coordinate on a reciprocal strategy towards the other group. All in all, interaction and within-group communication appears to have a positive effect on voter participation.

With respect to the second area of interest, first note that many elections involve elements of both simultaneous and sequential voting. In sequential voting, voters make their decisions knowing earlier voters' (turnout) decisions in the same election. In simultaneous voting, no voter receives information about any others' prior decision. ${ }^{4} \mathrm{~A}$ prime example where elements of both are mixed is in the US presidential primaries (e.g., Bartels, 1988; Morton and Williams, 1999, 2000). Morton and Williams (1999) argue that there, voting has been moving from sequential to simultaneous since states began (in the 1980s and 1990s) to move their primaries closer together at the beginning of the season. This shift yields more uninformed decisions, since voters have fewer opportunities to learn about the candidates from previous elections. Learning from early voters' decisions (e.g., about candidates, voter preferences, or 'states of the world') is at the core of most studies in this field. These investigate the ability of elections to aggregate information in models of incomplete information.

We know of a few prominent studies that (like ours) combine sequential with simultaneous voting. Morton and Williams (1999) explore US presidential primaries theoretically and experimentally by comparing pure simultaneous versus pure sequential voting over three candidates, where voting is mandatory. In the sequential setting, half of the voters simultaneously decide first. The outcome is made public, from which voters can learn about candidates' types. Then, the other half votes. In the experiment, Morton

\footnotetext{
${ }^{4}$ A third possible setting is a sequence of simultaneous elections. For example, McKelvey and Ordeshook (1985) study multiple elections with the same electorate to see whether players learn about voter preferences and candidate policies.
} 
and Williams find, i.a., that early voters generally vote informatively and that later voters use early outcomes to make decisions that better reflect their preferences.

Lohmann (1994a) models pre-election costly political action, through which voters can signal their private information about policy alternatives to other voters (e.g., through petitions and demonstrations). Lohmann (1994b) presents empirical evidence for this model. Observing the number of political actions, voters update their own information and cast a mandatory vote at the election stage. Lohmann finds, i.a., that political action prior to elections may be counterproductive, i.e. full-information voting outcomes become less likely with such action.

Dekel and Piccione (2000) present a voting game with incomplete information about others' preferences over two policy alternatives. Their main result is that (informative) symmetric equilibria of the game with simultaneous voting are equilibria for any sequential voting structure as well. The model includes endogenous timing of decisions and allows for both common and private values to the voters. Contrary to the previous two studies, this model includes the option to abstain in the elections. However, Battaglini (2004) shows that the main result no longer applies when voting costs are introduced.

The models discussed focus on the ability of sequential procedures to increase electoral efficiency by spreading private information (about policies or voter preferences) from early decisions to late voters. This is how they differ from our study, in which incomplete information is not essential. Rather, we are interested in the exchange of information about participation decisions within neighborhoods, where preferences are known (we only use incomplete information in one case, where voters do not know which candidate their neighbor supports).

Most closely related to our study is Jackson (1983). He empirically studies the effect on voter turnout of election night reporting, i.e. the projection of results before the end of the polls, during the 1980 US presidential election. This projection based on early East coast results is published before the East coast ballot boxes close. Obviously, the West coast voters still have even more hours to vote at that time. Prior to the 1980 election, a close race between Carter and Reagan was expected. However, surprisingly, the projection on the evening of election day clearly indicated Reagan as the victor. Jackson 
reports that this news decreased the turnout of voters who had not yet participated. Both, Democrats and Republicans, were negatively affected, though the Reagan supporters more strongly so. Jackson (1983, p.632) suggests "the early reporting of projections may only alter turnout in elections in which the projections differ from prior expectations. Elections in which people anticipate a close race, but in which the early returns and projections indicate the opposite, are the situations we expect to see a drop in turnout directly related to the media's coverage”.

We can compare Jackson's approach to ours. First, in his study 'late' voters receive information about aggregate turnout of a subgroup of voters, i.e., East coast citizens. In the NIE participation game, on the other hand, turnout information is on a much smaller scale, about a single voter. Secondly, as a consequence, Jackson’s study contains mixed information about participation of allies and adversaries, whereas our aim is to decompose the effects of these distinct kinds of information. Note that our laboratory experiment allow us to do so. Thirdly, the NIE participation game maintains an important feature of Jackson's study, namely that East coast citizens who had not yet voted, still had the opportunity to participate after the projection has been made public. This makes their situation comparable to senders in the NIE participation game. In this respect, our distinction between senders and receivers complements the empirical results of Jackson. Finally, the outcome in the 1980 US presidential election was expected to be close. In our study, we impose closeness by using equal group sizes (cf. Großer et al. 2004).

In essence, our study investigates a mix of sequential and simultaneous voting. Though such a mix seems to be realistic, our model cannot, for obvious reasons, represent all possible hybrids that exist outside the laboratory. Nevertheless, our approach allows us to carefully distinguish behavior in distinct roles and how this affects turnout. Aside from the direct interest in how information exchange affects participation, we are interested in the way behavior differs across senders and receivers as well as across distinct information conditions with respect to whether neighbors are allies or adversaries. In addition to the analysis outlined above, we investigate the importance of established bonds between group members. This is implemented by either keeping groups fixed over time ('partners') or mixing them before each election ('strangers'). Our conjecture is 
twofold: first, looking at previous comparisons of partners versus strangers in experimental participation games (Schram and Sonnemans, 1996a; Großer et al. 2004), we would expect higher participation by partners. Second, we expect that the relative importance of NIE is more important in strangers. With fixed groups, aggregate behavior is supposedly more predictable, which may decrease the value of observing the neighbor's decision as compared to the case when group composition varies. Hence, we would expect that receivers respond more to neighbors’ first stage decisions in strangers than in partners, and senders would anticipate this.

The remainder of this paper is organized as follows. Section 2 defines the NIE participation game and discusses its equilibria. In section 3, we describe the experimental design and in section 4 our experimental results are presented and analyzed. We conclude in section 5.

\section{THE NIE-PARTICIPATION GAME}

\subsection{THE GAME}

The NIE participation game has two stages. We assume an even and equal number of risk neutral players (voters) $N=N_{A}=N_{B}$ in each of two groups $i=A, B{ }^{5}$ Half of the voters in each group is of the type $S$ (ender), denoted by $j_{i, S}, i=A, B$, and the other half of the type $R$ (eceiver), $j_{i, R}, i=A, B$. Hence, each group consists of $N_{i, S}=N / 2$ senders and $N_{i, R}=N / 2$ receivers. Each voter knows her own type.

\section{DEFINITION 1 (neighborhood $\vartheta$ )}

A neighborhood $\vartheta$ is a matched pair of exactly one sender and one receiver.

Denote the neighbor of $j_{i, S}$ by $n\left(j_{i, S}\right)$ and the neighbor of $j_{i, R}$ by $n\left(j_{i, R}\right)$. Each voter is member of exactly one neighborhood. Hence, there are $N$ neighborhoods in the electorate.

\footnotetext{
${ }^{5}$ This is the setup in our experiments as well. Extensions to unequal group sizes are straightforward.
} 


\section{DEFINITION 2 (matching protocol $\Theta$ )}

We distinguish three matching protocols $\Theta$. The sender and receiver in a neighborhood are either from

1. the same group, $\vartheta \in \Theta_{\text {own }} \Rightarrow\left[j_{i, S} \in i \Leftrightarrow n\left(j_{i, S}\right) \in i\right] \wedge\left[j_{i, R} \in i \Leftrightarrow n\left(j_{i, R}\right) \in i\right]$;

2. different groups, $\vartheta \in \Theta_{\text {other }} \Rightarrow\left[j_{i, S} \in i \Leftrightarrow n\left(j_{i, S}\right) \notin i\right] \wedge\left[j_{i, R} \in i \Leftrightarrow n\left(j_{i, R}\right) \notin i\right]$;

3. an uncertain group, $\vartheta \in \Theta_{\text {uncertain }}$, where $\Theta_{\text {own }}$ occurs with probability $0<\operatorname{prob}\left(\Theta_{\text {own }}\right)<1$ and $\Theta_{\text {other }}$ with $\operatorname{prob}\left(\Theta_{\text {other }}\right)=1-\operatorname{prob}\left(\Theta_{\text {own }}\right)$.

All $N$ neighborhoods $\vartheta$ have the same matching protocol, which is common knowledge. The interpretation of definition 2 is that voters either know with certainty which candidate their neighbor supports $\left(\Theta_{\text {own }}\right.$ and $\left.\Theta_{\text {other }}\right)$, or have only probabilistic knowledge $\left(\Theta_{\text {uncertain }}\right)$ about her preferences. In the following, if the matching protocol $\Theta_{m}, m=$ own, other, uncertain, is not explicitly mentioned, a general case valid for all matching protocols will be under consideration.

The following structure and rules of the game are common knowledge to all players. At stage 1 all $N_{A, S}+N_{B, S}$ senders simultaneously decide whether to vote $v_{j_{i, S}}^{1}=1$, or abstain, $v_{j_{i, S}}^{1}=0, i=A, B$, where superscript ' 1 ' refers to stage 1 . Each receiver $j_{i, R}$ observes (only) the sender $n\left(j_{i, R}\right)$ 's decision and no other voter observes this decision. Senders who turn out to vote at stage 1 have no further decision to make, whereas senders who abstain at stage 1 have to decide again on voting at stage 2 .

At stage 2, all $N_{A, R}+N_{B, R}$ receivers and all senders who abstained at stage 1 simultaneously decide whether to vote, $v_{j_{i, S}}^{2}=1 ; v_{j_{i, R}}=1$, or abstain, $v_{j_{i, S}}^{2}=0 ; v_{j_{i, R}}=0$, $i=A, B$, where superscript ' 2 ' indicates stage 2 for senders. After all decisions have been made, voters are told the aggregate outcome of the election (the total number of votes cast in each group). No additional information about any other voter's turnout decision is given.

Aggregate turnout for $i=A, B$, is given by: 


$$
V_{i} \equiv \sum_{j_{i, S}}\left(v_{j_{i, S}}^{1}+v_{j_{i, S}}^{2}\right)+\sum_{j_{i, R}} v_{j_{i, R}}
$$

where $v_{j_{i, S}}^{1}+v_{j_{i, S}}^{2} \in\{0,1\}$, because senders can cast only one vote. For later use, we define the aggregate turnout of other voters in the same group as sender $j_{i, s}$, or receiver $j_{i, R}, i=A, B$, by

$$
\begin{gathered}
V_{i}^{-j_{i, S}} \equiv V_{i}-\left(v_{j_{i, S}}^{1}+v_{j_{i, S}}^{2}\right) ; \\
V_{i}^{-j_{i, R}} \equiv V_{i}-v_{j_{i, R}} .
\end{gathered}
$$

Revenues (the gross payoff to each member of the winning group) are denoted by $w$ and assumed to be equal for senders and receivers in a group $\left(w_{j_{i}}=w_{j_{i, S}}=w_{j_{i, R}}, i=A, B\right)$ :

$$
w_{j_{i}}\left(V_{i}, V_{-i}\right)=\left\{\begin{array}{lll}
0 & \text { if } & V_{i}<V_{-i} \\
1 / 2 & \text { if } & V_{i}=V_{-i} \\
1 & \text { if } & V_{i}>V_{-i},
\end{array}\right.
$$

$i=A, B$, where $-i$ refers to the opposing group. Furthermore, we assume identical participation costs to all voters, independent of type and stage, within the range $c \in(0,1)$, $\forall j_{i, S}, \forall j_{i, R}, i=A, B$. The common knowledge payoffs (denoted by $\pi$ ) for senders $j_{i, S}$, and receivers $j_{i, R}, i=A, B$, are then given by

$$
\begin{gathered}
\pi_{j_{i, S}}=w_{j_{i}}\left(V_{i}, V_{-i}\right)-\left(v_{j_{i, S}}^{1}+v_{j_{i, S}}^{2}\right) c ; \\
\pi_{j_{i, R}}=w_{j_{i}}\left(V_{i}, V_{-i}\right)-v_{j_{i, R}} c .
\end{gathered}
$$

In what follows, it will be useful to define the number of senders in group $i$, who vote at stage 1 by

$$
S_{i} \equiv \sum_{j_{i, S}} v_{j_{i, S}}^{1}
$$

In case of matching protocol $\Theta_{\text {own }}, S_{i}$ is also the number of receivers in $i$ who observe a sender voting at stage 1 . For matching protocol $\Theta_{\text {other }}$, this number is given by $S_{-i}$.

\subsection{NASH EQUILIBRIA}

For this game, we derive Nash equilibria. Because of the extensive (but straightforward) computations involved, we only give the general structure of the way in which these are 
derived. ${ }^{6}$ More details are available from the authors. Because notations can become cumbersome, we apply Kuhn's theorem (1953) by analyzing 'behavioral' rather than mixed strategies. This will allow us to consider strategies at each stage separately as opposed to strategies for the complete game.

First, we consider the four situations a voter in group $i=A, B$, facing matching protocol $\Theta_{m}, m=$ own, other, uncertain, might be in:

1) a sender deciding on $v_{j_{i, S}}^{1}\left(\Theta_{m}\right)$ at stage 1 ;

2) a sender having abstained at stage $1, v_{j, S}^{1}\left(\Theta_{m}\right)=0$, and deciding on $v_{j_{i, S}}^{2}\left(\Theta_{m}\right)$ at stage 2;

3a) a receiver deciding on $v_{j_{i, R}}\left(v_{n(j, R)}^{1}=0, \Theta_{m}\right)$ at stage 2 after observing her neighbor abstaining at stage 1 ;

3b) a receiver deciding on $v_{j_{i, R}}\left(v_{n\left(j_{i, R}\right)}^{1}=1, \Theta_{m}\right)$ at stage 2 after observing her neighbor voting at stage 1 .

Behavioral strategies for each of these situations are, respectively, the probabilities:

1) $\quad s_{j_{i, S}}\left(\Theta_{m}\right)$ that $v_{j_{i, S}}^{1}\left(\Theta_{m}\right)=1$;

2) $\quad a_{j_{i, S}}\left(\Theta_{m}\right)$ that $v_{j_{i, S}}^{2}\left(\Theta_{m}\right)=1$;

3a) $\quad a_{j_{i, R}}\left(\Theta_{m}\right)$ that $v_{j_{i, R}}\left(v_{n\left(j_{i, R}\right)}^{1}=0, \Theta_{m}\right)=1$;

3b) $\quad t_{j_{i, R}}\left(\Theta_{m}\right)$ that $v_{j_{i, R}}\left(v_{n\left(j_{i, R}\right)}^{1}=1, \Theta_{m}\right)=1$.

A voter will vote with probability 1 if the expected benefits minus the costs $c$ are higher than the expected benefits from abstention. She will mix when the two are equal. This yields the following four turnout conditions (7)-(10) for the situations distinguished.

CONDITION 1 (senders, stage 1):

Sender $j_{i, S}$ will vote with probability 1 at stage $1\left(s_{j_{i, S}}\left(\Theta_{m}\right)=1\right)$ iff

$$
\operatorname{Exp}_{\text {strat }_{1}}\left[\operatorname { E x p } _ { \text { strat } _ { 2 } } \left[\pi_{j_{i, S}} \mid v_{j_{i, S}}^{1}\left(\Theta_{m}\right)=1 \rrbracket>\operatorname{Exp}_{\text {strat }_{1}}\left[\operatorname { E x p } _ { \text { strat } _ { 2 } } \left[\pi_{j_{i, S}} \mid v_{j_{i, S}}^{1}\left(\Theta_{m}\right)=0 \rrbracket,\right.\right.\right.\right.
$$

\footnotetext{
${ }^{6}$ Given the results in Goeree and Holt (forthcoming) and Cason and Mui (2003), it would also be interesting to derive logit equilibria for this game. The game is too complex to derive these, however.
} 
where expectation operators are due to (i) strategic uncertainty about others' decisions at stage 1 ( strat $\left._{1}\right)$; and (ii) strategic uncertainty about others' decisions at stage $2\left(\right.$ strat $\left._{2}\right)$, given the number of votes at stage 1 in each group. Elaborating gives:

$$
\begin{aligned}
& \sum_{S_{i}=1}^{N / 2} \sum_{S_{-i}=0}^{N / 2} \operatorname{prob}\left[S_{i}\right] \operatorname{prob}\left[S_{-i}\right] \times \operatorname{prob}\left[V_{i}^{-j_{i, S}}+1>V_{-i} \mid\left(\Theta_{m}, S_{i}, S_{-i}\right)\right] \\
&\left.+\frac{1}{2} \operatorname{prob}\left[V_{i}^{-j_{i, S}}+1=V_{-i} \mid\left(\Theta_{m}, S_{i}, S_{-i}\right)\right]\right]-c \\
&>\sum_{S_{i}=0}^{N / 2-1} \sum_{S_{-i}=0}^{N / 2-0} \operatorname{prob}\left[S_{i}\right] \operatorname{prob}\left[S_{-i}\right] \times\left[\operatorname{prob}\left[V_{i}^{-j_{i, S}}>V_{i} \mid\left(\Theta_{m}, S_{i}, S_{-i}\right)\right]\right. \\
&\left.+\frac{1}{2} \operatorname{prob}\left[V_{i}^{-j_{i, S}}=V_{-i} \mid\left(\Theta_{m}, S_{i}, S_{-i}\right)\right]\right]-v_{j_{i, S}}^{2} c,
\end{aligned}
$$

$i=A, B$, for $m=o w n$,other . The $\operatorname{prob}[S]$ terms in (7) refer to the stage 1 votes by senders in the two groups. ${ }^{7}$ The first term after the multiplication operator on the left (right) hand side of the inequality describes the probability that this sender's group $i$ will win the election if she votes (abstains) and the second term describes the probability that $i$ will tie the election if $j_{i, S}$ votes (abstains) at stage 1 . Note that, in case of abstention at stage 1 , the sender still has to account for possible costs at stage 2 .

CONDITION 2 (senders, stage 2): Similarly, sender $j_{i, S}$ will vote with probability 1 at stage 2 iff the expected payoff of turnout is higher than that of abstention:

$$
\begin{array}{r}
\sum_{S_{i}=0}^{N / 2-1} \sum_{S_{-i}=0}^{N / 2-0} \operatorname{prob}\left[S_{i}\right] \operatorname{prob}\left[S_{-i}\right] \times\left[\operatorname{prob}\left[V_{i}^{-j_{i, S}}+1>V_{-i} \mid\left(\Theta_{m}, v_{j_{i, S}}^{1}=0, S_{i}, S_{-i}\right)\right]\right. \\
\left.+\frac{1}{2} \operatorname{prob}\left[V_{i}^{-j_{i, S}}+1=V_{-i} \mid\left(\Theta_{m}, v_{j_{i, S}}^{1}=0, S_{i}, S_{-i}\right)\right]\right]-c
\end{array}
$$

\footnotetext{
${ }^{7}$ Note that $S_{i} \in\{1, \ldots, N / 2\}$ if a sender participates at stage 1 and $S_{i} \in\{0, \ldots, N / 2\}$ if she abstains. This is reflected in the summation in (eq. 7).
} 


$$
\begin{gathered}
>\sum_{S_{i}=0}^{N / 2-1} \sum_{S_{-i}=0}^{N / 2-0} \operatorname{prob}\left[S_{i}\right] \operatorname{prob}\left[S_{-i}\right] \times\left[\operatorname{prob}\left[V_{i}^{-j_{i, S}}>V_{-i} \mid\left(\Theta_{m}, v_{j_{i, S}}^{1}=0, S_{i}, S_{-i}\right)\right]\right. \\
\left.+\frac{1}{2} \operatorname{prob}\left[V_{i}^{-j_{i, S}}=V_{-i} \mid\left(\Theta_{m}, v_{j_{i, S}}^{1}=0, S_{i}, S_{-i}\right)\right]\right],
\end{gathered}
$$

$i=A, B$, for $m=$ own, other . Rearranging gives

$$
\begin{aligned}
\sum_{S_{i}=0}^{N / 2-1} \sum_{S_{-i}=0}^{N / 2-0} \operatorname{prob}\left[S_{i}\right] \operatorname{prob}\left[S_{-i}\right] & \times\left[\operatorname{prob}\left[V_{i}^{-j_{i, S}}+1=V_{-i} \mid\left(\Theta_{m}, v_{j_{i, S}}^{1}=0, S_{i}, S_{-i}\right)\right]\right. \\
& \left.+\operatorname{prob}\left[V_{i}^{-j_{i, S}}=V_{-i} \mid\left(\Theta_{m}, v_{j_{i, S}}^{1}=0, S_{i}, S_{-i}\right)\right]\right]>2 c
\end{aligned}
$$

CONDITION 3a (receivers at stage 2 after observing abstention): Given $v_{n\left(j_{i, R}\right)}^{1}=0$, the expected payoff from voting exceeds that from abstention when:

$$
\begin{array}{r}
\sum_{S_{i}=0}^{N / 2-x} \sum_{S_{-i}=0}^{N / 2-y} \operatorname{prob}\left[S_{i}\right] \operatorname{prob}\left[S_{-i}\right] \times\left[\operatorname{prob}\left[V_{i}^{-j_{i, R}}+1>V_{-i} \mid\left(\Theta_{m}, v_{n\left(j_{i, R}\right)}^{1}=0, S_{i}, S_{-i}\right)\right]\right. \\
\left.+\frac{1}{2} \operatorname{prob}\left[V_{i}^{-j_{i, R}}+1=V_{-i} \mid\left(\Theta_{m}, v_{n\left(j_{i, R}\right)}^{1}=0, S_{i}, S_{-i}\right)\right]\right]-c \\
>\sum_{S_{i}=0}^{N / 2-x} \sum_{S_{-i}=0}^{N / 2-y} \operatorname{prob}\left[S_{i}\right] \operatorname{prob}\left[S_{-i}\right] \times\left[\operatorname{prob}\left[V_{i}^{-j_{i, R}}>V_{-i} \mid\left(\Theta_{m}, v_{n\left(j_{i, R}\right)}^{1}=0, S_{i}, S_{-i}\right)\right]\right. \\
\left.+\frac{1}{2} \operatorname{prob}\left[V_{i}^{-j_{i, R}}=V_{-i} \mid\left(\Theta_{m}, v_{n\left(j_{i, R}\right)}^{1}=0, S_{i}, S_{-i}\right)\right]\right],
\end{array}
$$

$i=A, B$, where $x=1 ; y=0$ for $m=o w n$, and $x=0 ; y=1$ for $m=$ other.$^{8}$ Rearranging gives

\footnotetext{
${ }^{8}$ In own, $S_{i} \in\{0, \ldots, N / 2-1\}$ because $i$ observed a stage 1 abstention in the own group. Similarly $S_{-i} \in\{0, \ldots, N / 2-1\}$ in other.
} 


$$
\begin{array}{r}
\sum_{S_{i}=0}^{N / 2-x} \sum_{S_{-i}=0}^{N / 2-y} \operatorname{prob}\left[S_{i}\right] \operatorname{prob}\left[S_{-i}\right] \times\left[\operatorname{prob}\left[V_{i}^{-j_{i, R}}+1=V_{-i} \mid\left(\Theta_{m}, v_{n\left(j_{i, R}\right)}^{1}=0, S_{i}, S_{-i}\right)\right]\right. \\
\left.+\operatorname{prob}\left[V_{i}^{-j_{i, R}}=V_{-i} \mid\left(\Theta_{m}, v_{n\left(j_{i, R}\right)}^{1}=0, S_{i}, S_{-i}\right)\right]\right]>2 c
\end{array}
$$

CONDITION 3b (stage 2): (receivers at stage 2 after observing a vote): Given $v_{n\left(j_{i, R}\right)}^{1}=1$, the expected payoff from voting exceeds that from abstention when:

$$
\begin{aligned}
& \sum_{S_{i}=x}^{N / 2} \sum_{S_{-i}=y}^{N / 2} \operatorname{prob}\left[S_{i}\right] \operatorname{prob}\left[S_{-i}\right] \times {\left[\operatorname{prob}\left[V_{i}^{-j_{i, R}}+1>V_{-i} \mid\left(\Theta_{m}, v_{n\left(j_{i, R}\right)}^{1}=1, S_{i}, S_{-i}\right)\right]\right.} \\
&+\left.\frac{1}{2} \operatorname{prob}\left[V_{i}^{-j_{i, R}}+1=V_{-i} \mid\left(\Theta_{m}, v_{n\left(j_{i, R}\right)}^{1}=1, S_{i}, S_{-i}\right)\right]\right]-C \\
&>\sum_{S_{i}=x}^{N / 2} \sum_{S_{-i}=y}^{N / 2} \operatorname{prob}\left[S_{i}\right] \operatorname{prob}\left[S_{-i}\right] \times\left[\operatorname{prob}\left[V_{i}^{-j_{i, R}}>V_{-i} \mid\left(\Theta_{m}, v_{n\left(j_{i, R}\right)}^{1}=1, S_{i}, S_{-i}\right)\right]\right. \\
&\left.+\frac{1}{2} \operatorname{prob}\left[V_{i}^{-j_{i, R}}=V_{-i} \mid\left(\Theta_{m}, v_{n\left(j_{i, R}\right)}^{1}=1, S_{i}, S_{-i}\right)\right]\right],
\end{aligned}
$$

$i=A, B$, where $x=1 ; y=0$ for $m=$ own, and $x=0 ; y=1$ for $m=$ other $^{9}$ Rearranging gives

$$
\begin{aligned}
\sum_{S_{i}=x}^{N / 2} \sum_{S_{-i}=y}^{N / 2} \operatorname{prob}\left[S_{i}\right] \operatorname{prob}\left[S_{-i}\right] & \times\left[\operatorname{prob}\left[V_{i}^{-j R}+1=V_{-i} \mid\left(\Theta_{m}, v_{n\left(j_{i, R}\right)}^{1}=1, S_{i}, S_{-i}\right)\right]\right. \\
& \left.+\operatorname{prob}\left[V_{i}^{-j_{i, R}}=V_{-i} \mid\left(\Theta_{m}, v_{n\left(j_{i, R}\right)}^{1}=1, S_{i}, S_{-i}\right)\right]\right]>2 c
\end{aligned}
$$

The conditions for $\Theta_{\text {uncertain }}$ are a probability mix of the respective conditions with probabilities $\operatorname{prob}\left(\Theta_{\text {own }}\right)$ and $\operatorname{prob}\left(\Theta_{\text {other }}\right)$. This gives a game of incomplete information.

\footnotetext{
${ }^{9}$ Now, $i$ observes a stage 1 vote, so $S_{i} \in\{1, \ldots, N / 2\}$ in own and $S_{-i} \in\{1, \ldots, N / 2\}$ in other.
} 
Next, we define the equilibria considered for this NIE participation game.

DEFINITION 3 (Quasi-symmetric equilibrium)

An equilibrium in behavioral strategies in the NIE participation game is quasi-symmetric if it holds that:

$$
\begin{aligned}
& s_{j_{i, S}}=s_{h_{k, S}} \equiv s \quad \in[0,1], \forall j_{i, S}, h_{k, S}, \quad i, k=A, B, \\
& a_{j_{i, S}}=a_{h_{k, S}} \equiv a_{S} \in[0,1], \forall j_{i, S}, h_{k, S}, \quad i, k=A, B, \\
& a_{j_{i, R}}=a_{h_{k, R}} \equiv a_{R} \in[0,1], \forall j_{i, R}, h_{k, R}, \quad i, k=A, B, \text { and } \\
& t_{j_{i, R}}=t_{h_{k, R}} \equiv t \in[0,1], \forall j_{i, R}, h_{k, R}, \quad i, k=A, B .
\end{aligned}
$$

In words, all voters in any particular decision situation play the same behavioral strategy, independent of the group they are in. This reduces our equilibrium analysis to four strategies. The equilibrium is denoted by 'quasi-symmetric' because strategies are not limited to be symmetric across players in different positions.

PROPOSITION (Quasi-symmetric Nash equilibria in pure strategies):

(i) If $c>1 / 2$, the only Nash equilibrium is where nobody votes: $v_{j_{i, S}}^{1}\left(\Theta_{m}\right)=0$, $v_{j_{i, S}}^{2}\left(\Theta_{m}\right)=0, \quad v_{j_{i, R}}\left(v_{n\left(j_{i, R}\right)}^{1}=0, \Theta_{m}\right)=0, \quad v_{j_{i, R}}\left(v_{n\left(j_{i, R}\right)}^{1}=1, \Theta_{m}\right)=0, \quad \forall j_{i, S}, \quad \forall j_{i, R}$, $i=A, B, m=$ own, other, uncertain .

(ii) If $c<1 / 2$, the only Nash equilibria in pure strategies are where everybody votes:

$$
\begin{aligned}
& {\left[v_{j_{i, S}}^{1}\left(\Theta_{m}\right)=1 \wedge v_{j_{i, S}}^{2}\left(\Theta_{m}\right)=0\right] \vee\left[v_{j_{i, S}}^{1}\left(\Theta_{m}\right)=0 \wedge v_{j_{i, S}}^{2}\left(\Theta_{m}\right)=1\right],} \\
& v_{j_{i, R}}\left(v_{n\left(j_{i, R}\right)}^{1}=0, \Theta_{m}\right)=1, \text { and } v_{j_{i, R}}\left(v_{n\left(j_{i, R}\right)}^{1}=1, \Theta_{m}\right)=1, \quad \forall j_{i, S}, \quad \forall j_{i, R}, \quad i=A, B, \\
& m=\text { own, other, uncertain. }
\end{aligned}
$$

Proof (straightforward application of Palfrey and Rosenthal, 1983, for equal group sizes). 
To find quasi-symmetric equilibria in behavioral strategies (separately for the distinct information conditions $\Theta_{m}$ ), first the decision at stage 2 is elaborated (backwards induction), using conditions (8), (9) and (10) stated as equalities. The probabilities in these equations are tedious but straightforward combinations of binomials using the probabilities defined in definition 3 . This gives three equations for the four probabilities $s, a_{S}, a_{R}$, and $t$. Senders at stage 1 anticipate the best responses implicit in these equations and will mix with a probability $s$ that equates the expected value of voting and abstaining (eq. 7), once again involving a combination of binomials. This gives a fourth equation for the four probabilities. In the following section, we will present the equilibria derived for the parameters in our experiments.

\section{EXPERIMENTAL DESIGN}

The computerized ${ }^{10}$ experiment was run between April and June 2001 at the laboratory of the Center for Research in Experimental Economics and political Decision making (CREED) of the University of Amsterdam. Subjects were recruited from the university's undergraduate population. 168 subjects participated in 10 sessions. Each session lasted about 2 hours ( $c f$. appendix B for the read-aloud instructions). Earnings in the experiment are measured in tokens. At the end of a session token earnings were transferred to cash at a rate of 4 tokens to one Dutch Guilder ( $\approx € 0.45$ ). On average, subjects earned 48.66 Guilders.

Each electorate consists of 12 voters: two groups of 6 subjects each. In 4 sessions, two electorates participated simultaneously, and 6 sessions were held with one electorate each. In sessions with more than one electorate, there is no interaction of any kind between subjects in different electorates. This is known to all subjects. Hence, each of the 14 electorates in our sessions provides us with one independent observation. Each subject is either sender or receiver throughout the experiment and knows her role from the beginning of the session. There are always 3 senders and 3 receivers in each group.

\footnotetext{
${ }^{10}$ RatImage (Abbink and Sadrieh, 1995) was used to program the software.
} 
Our first treatment is related to the matching protocol of subjects within an electorate, where we distinguish 'partners' and 'strangers' (cf. Andreoni, 1988). In 'partners', subjects in an electorate are randomly allocated to groups at the beginning of the first round, and groups remain constant thereafter. In 'strangers', groups are randomly rematched at the beginning of each round. Note that strangers do remain in the same electorate across rounds; they are only reallocated to the two groups the electorate consists of. A natural interpretation of partners versus strangers in this context is that partners constitute an electorate of voters who remain loyal to their party across elections. Strangers can be seen as 'floating voters' who may switch from one party to another between elections ( $c f$. Großer et al. 2004). Of course, partners and strangers are varied in a between-subject design.

Our second treatment is varied in a within subject design. This deals with the information about the neighbor's vote. If voters are 'informed', we distinguish rounds in which neighbors are from the same ('own') and different ('other') groups, and rounds in which 'own' and 'other' each occur with probability of 0.5 ('uncertain'). As a control, we organized four 'uninformed' electorates in which no information about others' votes was provided. In these sessions we keep the decision structure as close as possible to 'informed' by maintaining the two decision making stages described above as well as the labels 'sender' and 'receiver'. In the analysis below, we will refer to subjects in these sessions as neighbors, senders, and receivers even though no information was exchanged between them.

Each session lasts 99 decision rounds. 33 rounds use the information condition 'own', 33 use 'other', and 33 use 'uncertain'. ${ }^{11}$ This is varied in a random, but predetermined manner (see the table in Appendix A-1 for the complete sequence). In each round, each subject in the winning group receives a revenue of 4 tokens and each subject in the losing

\footnotetext{
${ }^{11}$ We chose to vary the structure of preferences in neighborhoods in a within-subject design (33 rounds of each information condition) in order to restrict the number of electorates needed. On the other hand, we decided to study the uninformed case in separate sessions in order to link our experiment to previous experimental participation games. As a consequence, uninformed subjects made 99 decisions in the same setting, whereas informed subjects made 33 decisions in each of the three conditions. The differences between uninformed and informed are so strong (and stay strong if we only consider the first 33 or the last 33 rounds of uninformed), that we are confident that the number of rounds did not affect the results that we will present below.
} 
group of 1 token. Participation costs are 1 token, independent of a subject's role. Hence, negative payoffs are avoided. Table 1 summarizes treatments and parameters.

TABLE 1: SUMMARY OF TREATMENTS AND PARAMETERS

\begin{tabular}{|l|c|c|c|c|c|c|}
\hline Treatment & $\begin{array}{c}\text { \# Rounds } \\
\text { (per info- } \\
\text { condition) }\end{array}$ & $\begin{array}{c}\text { Revenue } \\
\text { win } \\
\text { (lose) }\end{array}$ & $\begin{array}{c}\text { Partici- } \\
\text { pation } \\
\text { costs }\end{array}$ & $\begin{array}{c}\text { Size of } \\
\text { electorate } \\
\text { (groups) }\end{array}$ & $\begin{array}{c}\text { \# Senders } \\
\text { (receivers) } \\
\text { per group }\end{array}$ & $\begin{array}{c}\text { Independent } \\
\text { observations } \\
\text { (sessions) }\end{array}$ \\
\hline IP & $99(33)$ & $4(1)$ & 1 & $12(6)$ & $3(3)$ & $5(3)$ \\
\hline IS & $99(33)$ & $4(1)$ & 1 & $12(6)$ & $3(3)$ & $5(3)$ \\
\hline US & $99(33)$ & $4(1)$ & 1 & $12(6)$ & $3(3)$ & $4(4)$ \\
\hline
\end{tabular}

Note: 'I' = 'informed', 'U' = ‘uninformed', 'P' = 'partners', and 'S' = 'strangers'.

For these parameters, we can derive the quasi-symmetric Nash equilibria as described in section 2 for the stage game. Normalizing revenue to lie between 0 and 1 , we have $c=1 / 3$. Following the proposition, we conclude that everyone casting a vote (with senders casting it either at stage 1 or at stage 2) is a Nash equilibrium in pure strategies ${ }^{12}$. For $m=o w n$ and $m=$ other , the quasi-symmetric equilibria in behavioral strategies ${ }^{13}$ for the stage game are given in table 2. For $m=$ uncertain, no such equilibria exist. Using backwards induction, these equilibria hold for each round, in partners and strangers. ${ }^{14}$

TABLE 2: QUASI-SYMMETRIC NASH EQUILIBRIA IN BEHAVIORAL STRATEGIES

\begin{tabular}{|c|c|c|c|c|c|c|c|c|}
\hline \multicolumn{2}{|c|}{ Treatment } & $S$ & $a_{S}$ & $\begin{array}{c}\text { Expected } \\
\text { turnout } \\
\text { senders }\end{array}$ & $t$ & $a_{R}$ & $\begin{array}{c}\text { Expected } \\
\text { turnout } \\
\text { receivers }\end{array}$ & $\begin{array}{c}\text { Expected } \\
\text { turnout }\end{array}$ \\
\hline \multirow{4}{*}{ Informed } & \multirow{2}{*}{ own } & .791 & 1 & 1 & .119 & 1 & .303 & .652 \\
\hline & & .689 & 1 & 1 & .560 & 1 & .697 & .848 \\
\hline & other & .406 & .839 & .904 & .764 & 1 & .904 & .904 \\
\hline & uncertain & \multicolumn{7}{|c|}{-} \\
\hline \multicolumn{2}{|c|}{ Uninformed } & \multicolumn{7}{|c|}{.107 or $.893^{*}$} \\
\hline
\end{tabular}

Strategies: $s=$ senders at stage $1 ; a_{S}=$ senders at stage $2 ; t=$ receivers after observing participation, $a_{R}=$ receivers after observing abstention.

*Any combination of probabilities $s$ and $a_{S}$ that yields $s+(1-s) a_{S}=.107$ or .893 is an equilibrium.

\footnotetext{
12 This is easy to confirm for the parameters chosen. A unilateral deviation from $100 \%$ turnout saves 1 token but decreases the expected revenue from 2.5 to 1 .

${ }^{13}$ In some cases, some voters do not mix in equilibrium.

${ }^{14}$ We abstract from coordination on Pareto dominant equilibria by means of punishment by playing the inefficient pure strategy equilibrium where everybody participates.
} 
Note that there are two equilibria for $m=o w n .{ }^{15}$ Moreover, equilibria are the same for partners and strangers. Table 2 shows that expected overall participation is higher for other (.904) than for own (.652 and .848). ${ }^{16}$ Uninformed provides the lowest (.107) and a very high (.893) expected turnout, which makes it difficult to formulate comparative statics predictions vis-à-vis the informed cases. For informed, a comparison of equilibria does provide such predictions, however. In the equilibria for own, senders participate at substantially higher rates than receivers in both equilibria (1 vs. .303 and 1 vs. .697), whereas they participate at equal rates (.904) in the equilibrium for other. Also, note that in all cases, in equilibrium, senders participate at higher rates at stage 2 than at stage 1 . Note that stage 2 participation rates are defined as the fraction of senders that abstained at stage 1 . As a fraction of all senders, participation is higher at stage 1 than at stage 2 in own (.791 vs. .209 and .689 vs. .311), and higher at stage 2 in other (.406 vs. .498). Finally, equilibrium participation by receivers is higher after observing abstention than after observing a sender casting a vote. The difference is largest for own.

Summarizing, we can use these Nash equilibria to formulate five hypotheses with respect to the comparative statics between own and other in our design:

H1: Turnout is higher when neighbors are adversaries than when they are allies.

H2: When they are allies, senders participate at a higher rate than receivers.

H3: $\quad$ Senders participate at higher rates at stage 2 than at stage 1.

H4: $\quad$ Receivers participate more after observing abstention than after observing a vote.

H5: After observing a vote, receivers are more likely to participate if the neighbor is an adversary than in case of an ally.

We will return to these comparative statics, when presenting our results.

\footnotetext{
15 The two equilibrium strategies for receivers are also a 'low' (.303) and 'high' (.697) equilibrium in the standard participation game (Palfrey and Rosenthal, 1983) with the same voting costs but two groups of equal size 3 . This is intuitive, since all 6 senders vote with probability 1 in own, hence creating a tie and the remaining receivers play a participation game of three against three.

${ }^{16}$ Because full participation is an equilibrium for all cases, we do not use this when predicting differences across treatments.
} 


\section{EXPERIMENTAL RESULTS}

This section presents and analyzes our experimental results. We start with overall participation for all treatments, followed by an investigation of participation rates in the three information conditions. Then, our focus will be on behavior of senders at stages 1 and 2 and receivers. For the latter, we distinguish between cases where they observed turnout or abstention by their sender-neighbors. After discussing electoral efficiency and realized earning distributions, we will try to put the pieces of the puzzle together and get a grasp of what the effect of NIE is. For our analysis we use nonparametric statistics as described in Siegel and Castellan, Jr. (1988). As mentioned above, our data provide independent observations at the electorate level. Therefore, all of our tests will be conducted at the electorate level.

\subsection{Aggregate Participation Rates}

Figure 1 gives aggregate participation rates averaged over blocks of 20 rounds each (19 rounds in the last block).

FigURE 1: AGGREGATE PARTICIPATION RATES.

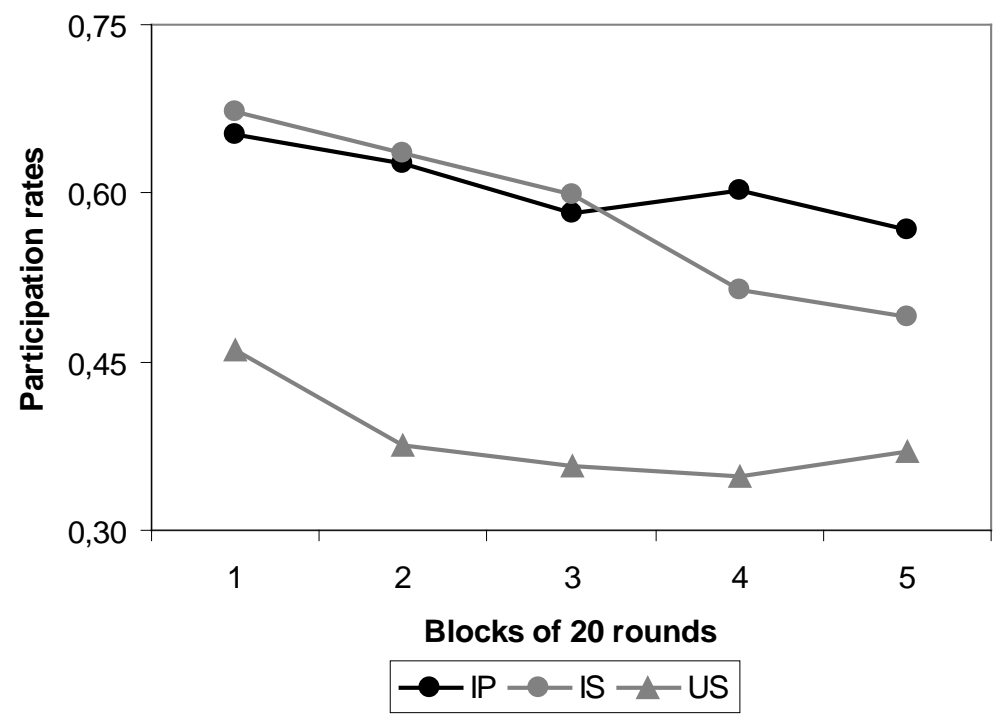

RESULT 1: Neighborhood information exchange increases turnout.

Aggregate average participation rates are substantially higher when information is exchanged (IS) than when it is not (US). IS starts at an average participation of $67 \%$ in 
rounds $1-20$ and ends at $49 \%$ in rounds $81-99$. At the same time, average participation in US varies between $46 \%$ and $37 \%$. The null hypothesis of no difference is clearly rejected at the electorate level: there is not one observation in US that exceeds those in IS (onetailed Wilcoxon-Mann-Whitney test, 1\% significance level).

\section{RESULT 2: $\quad$ The stability of group composition does not affect turnout.}

In our design, the stability of group composition is varied by way of our partners versus strangers treatments. IP and IS start at participation rates of $65 \%$ and $67 \%$, respectively, decreasing to $57 \%$ and $49 \%$. A Wilcoxon-Mann-Whitney test cannot reject the null hypothesis of no difference (10\% significance level, two-tailed test). ${ }^{17}$

In US, observed aggregate participation rates are at similar levels to those observed in previous experimental studies on participation games without information exchange. For example, Schram and Sonnemans (1996a) report average turnout rates of 31\% (42\%) for the winner-takes-all case with two groups of 6 players in strangers (partners). For strangers, this is somewhat lower than what we observe in US (38\%). Aggregate participation rates in the two informed treatments are much higher than previously observed for both partners and strangers.

We can also compare our results to the Nash equilibria shown in Table 2. It appears that turnout is lower than predicted by the quasi-symmetric equilibria for informed voters and between the two predictions for the uninformed. ${ }^{18}$ We will consider the relationship between observed behavior and equilibrium predictions in more detail, below.

\subsection{PARTICIPATION RATES PER INFORMATION CONDITION}

Figure 2 shows participation rates disaggregated for the information conditions own, other, and uncertain for IP and IS, respectively. ${ }^{19}$

\footnotetext{
${ }^{17}$ Figure 1 suggests that a difference may occur in the last two blocks. The test does not reject the null hypothesis of no differences for these blocks either, however.

${ }^{18}$ For this aggregate case, we cannot conclude much about the comparative statics implied by the equilibria. For one of the two equilibria for US, the observed higher participation by the informed is in line with the equilibrium comparative statics, for the other it is not.

${ }^{19}$ The number of observations per block differs across information conditions because each condition is used 33 times in a predefined random sequence. In block $1(2 ; 3 ; 4 ; 5)$, own was used 6 (9; 6; 5; 7), other 5 (7; 8; 8; 5), and uncertain $9(4 ; 6 ; 7 ; 7)$ times (cf. Appendix A-1).
} 
Figure 2A: PARTICIPATION RATES PER INFORMATION CONDITION IN IP.

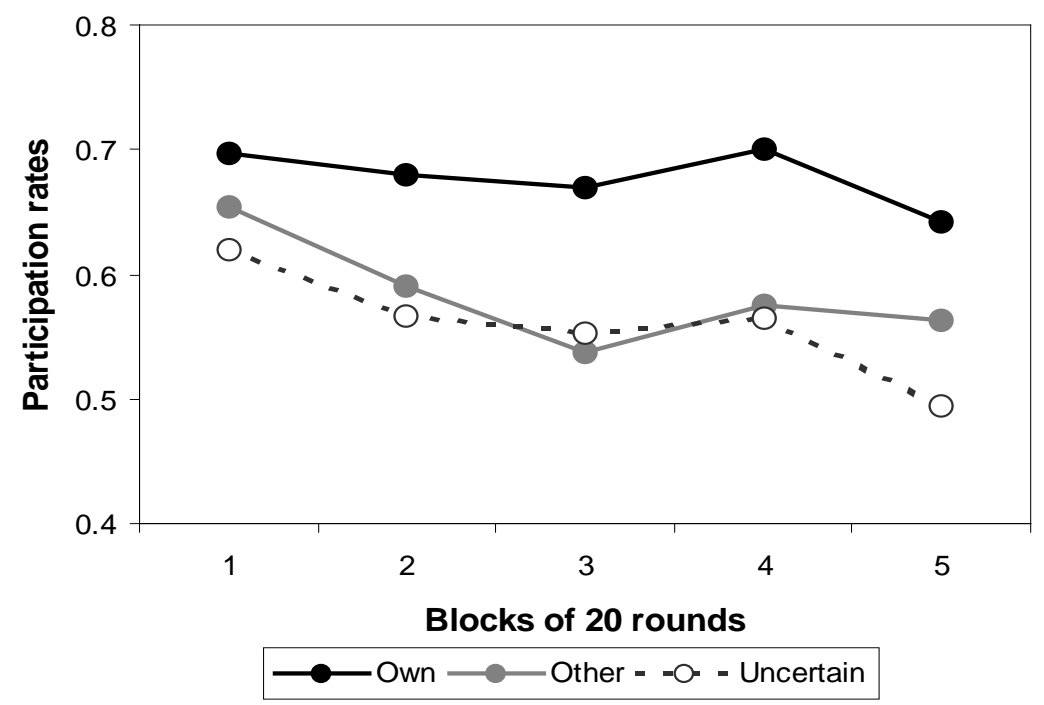

FIGURE 2B: PARTICIPATION RATES PER INFORMATION CONDITION IN IS.

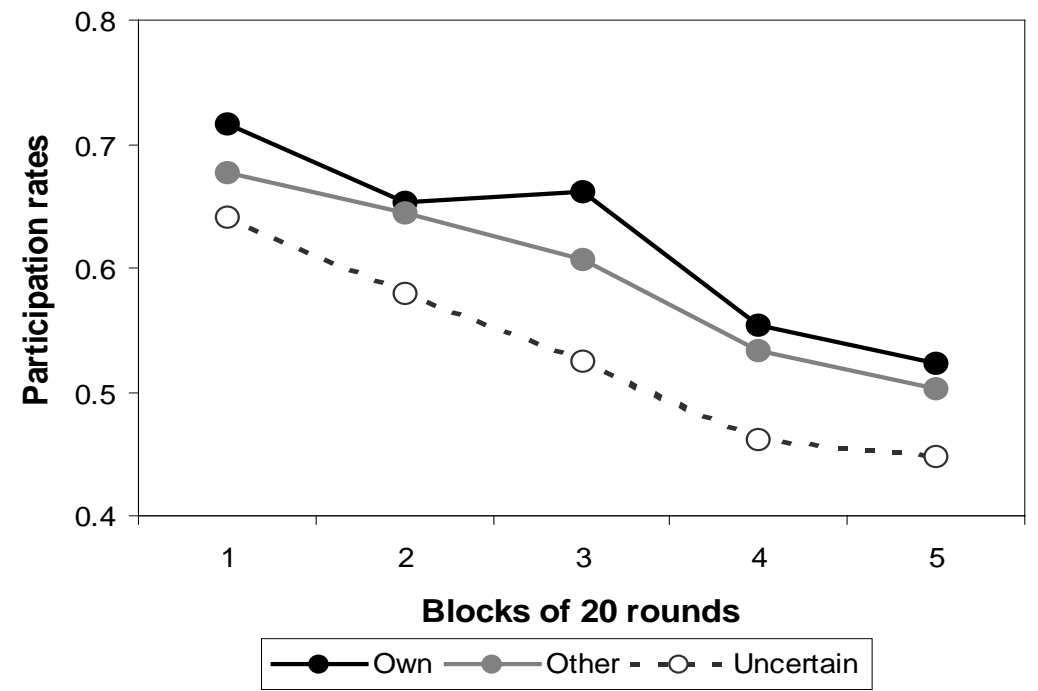

RESULT 3: When information is exchanged, turnout is highest amongst allies and lowest when neighbors do not know each other's preferences.

We observe the same ranking of participation in both figures, with average participation rates highest in own and lowest in uncertain. This ranking is observed in all blocks of rounds, except one. A Friedman two-way analysis of variance by ranks rejects the null hypothesis of no ordering in favor of this ranking at the 5\% significance level for IP and 
at $1 \%$ significance for IS. The same test does not find significant differences for US (10\% significance level), for which we do not provide a figure.

Note the distinct dynamics across information conditions. When relationships are fixed (IP), participation remains stable (at approximately 70\%) for allies. In other and uncertain, however, turnout decreases from the first to the second block of rounds and then remains more or less stable (except for a drop in the last block of uncertain). With changing groups (IS), participation decreases more or less steadily across rounds.

Our results that turnout is highest in own and that this effect is especially strong with fixed groups supports studies suggesting that segregation increases participation (e.g., Takács 2001, 2002). The result that participation is lowest with uncertainty about the neighbor's preferences may seem surprising. Intuitively, one would expect participation in uncertain to lie between that in own and other. Apparently, the additional source of uncertainty drives down participation. A similar observation is made in Großer et al. (2004), where participation rates are lower when uncertainty about others' preferences is introduced.

Compare result 3 to the first of the comparative statics derived from the equilibrium predictions in section 3 . $\mathrm{H} 1$ predicts that turnout is higher when neighbors are adversaries than when they are allies. We observe the opposite. In section 4.7, we will discuss what may be driving this rejection of the equilibrium prediction.

\subsection{COMPARING PARTICIPATION RATES FOR SENDERS AND RECEIVERS}

Table 3 gives the participation rates per treatment, role, and stage across all rounds. We start with a comparison of participation by senders and receivers.

RESULT 4: Senders participate at a higher rate than receivers do.

There are 9 possible comparisons for sender and receiver turnout (3 information conditions in each of IP, IS, US). Only when neighbors are uncertain about each others' preferences in IP do we observe (non-significant) higher turnout for receivers. Aggregating across information conditions, we always observe higher turnout by senders, though the difference is relatively low in IP (3\%-points), compared to IS (12\%-points) and US (15\%-points). Wilcoxon signed ranks tests reject the null hypothesis of no 
difference for IS and US in favor of higher rates for senders (10\% significance level, onetailed tests), but cannot reject it for IP at the same significance level. When testing for each information condition separately, we reject the null in favor of higher turnout by senders in 4 out of 9 cases.

TABLE 3: PARTICIPATION RATES

\begin{tabular}{|c|c|c|c|c|c|c|c|c|}
\hline \multirow{3}{*}{\multicolumn{2}{|c|}{ Treatment }} & \multicolumn{7}{|c|}{ Participation rates } \\
\hline & & \multicolumn{3}{|c|}{ Senders } & \multicolumn{3}{|c|}{ Receivers } & \multirow{2}{*}{$\begin{array}{c}\text { All } \\
\text { Total } \\
\end{array}$} \\
\hline & & $\begin{array}{c}\text { Stage } \\
1\end{array}$ & $\begin{array}{c}\text { Stage } \\
2 *\end{array}$ & Total & $\begin{array}{c}\text { Turnout } \\
\text { observed }\end{array}$ & $\begin{array}{c}\text { Abstention } \\
\text { observed }\end{array}$ & Total & \\
\hline \multirow{4}{*}{ IP } & own & .634 & .251 & .726 & .631 & .619 & .626 & .676 \\
\hline & other & .277 & .432 & .589 & .518 & .589 & .570 & .579 \\
\hline & uncertain & .371 & .279 & .546 & .659 & .533 & .580 & .563 \\
\hline & Total & .427 & .321 & .621 & .603 & .580 & .592 & .606 \\
\hline \multirow{4}{*}{ IS } & own & .619 & .268 & .721 & .586 & .430 & .526 & .624 \\
\hline & other & .388 & .434 & .654 & .557 & .513 & .530 & .592 \\
\hline & uncertain & .366 & 298 & .555 & .580 & .473 & .512 & .533 \\
\hline & Total & .458 & .333 & .643 & .574 & .472 & .523 & .583 \\
\hline \multirow{4}{*}{ US } & own & .376 & .111 & .446 & .376 & .318 & .340 & .393 \\
\hline & other & .394 & .110 & .461 & .276 & .308 & .295 & .378 \\
\hline & uncertain & .367 & .142 & .457 & .285 & .297 & .293 & .375 \\
\hline & Total & .379 & .121 & .455 & .312 & .308 & .309 & .382 \\
\hline
\end{tabular}

*Turnout as a fraction of senders making a decision at stage 2 .

The higher participation of senders than receivers in US (where no information is exchanged) comes as a surprise. Note that receivers participate at the same rate (31\%) as subjects Schram and Sonnemans (1996a), where no NIE takes place. This result suggests an influence on participation by senders of the two-stage decision procedure itself. We can think of three possible explanations. First, there may be a 'timing effect' where first movers behave differently than second movers, even when no information is exchanged (see, e.g., Rapoport, 1997; Weber et al., 2004). Second, the labels 'sender' and 'receiver' may cause a 'framing effect' (see, e.g., Tversky and Kahneman, 1981), provoking senders to participate more. Third, the freedom to delay the decision, i.e. because the 
exact same alternative occurs again at stage 2, may be an explanation for our finding. Because US is only used as a benchmark, we will not elaborate on this finding. Note that participation by both senders and receivers in all of the IP and IS conditions is (much) higher than that of senders in US.

Result 4 allows us to test the second hypothesis on comparative statics. H2 predicts that, when allies, senders participate at a higher rate than receivers do. This is supported by the numbers in table 3. One-tailed Wilcoxon signed ranks tests show that the higher turnout of senders is not statistically significant when the allies are partners (at the 10\%level), but it is when they are strangers (5\%-level). When IP and IS are aggregated, the difference is statistically significant as well (1\%-level).

\subsection{SENDER BEHAVIOR}

In aggregate, senders' participate most in IS and least in US (cf. table 3). WilcoxonMann-Whitney tests show that the differences between IP and US (62\% vs. 46\%) and IS and US (64\% vs. 46\%) are statistically significant at the $1 \%$ level, but the null that senders participate at the same rate in IS and IP (64\% vs. 62\%) is not rejected at the $10 \%$ level (all one-tailed tests).

We can use table 3 to have a closer look at result 3, that turnout is highest amongst allies, followed by adversaries. It is lowest for neighbors facing uncertainty about each other's preferences. From table 3 it appears that this ranking is mainly caused by the senders. Differences across information conditions appear to be smaller for receivers. For example, in strangers, there is almost no difference in aggregate receiver behavior across the conditions. In fact, for receivers, the differences are not significant in either IP or IS (Friedman two-way analysis of variance by ranks, 10\% significance level). In contrast, the differences are significant in both IP (5\%-level) and IS (1\%-level) for senders. Apparently, senders play a crucial role in the aggregate result. Therefore, we now turn to a separate analysis of both types, senders and receivers.

Of course, senders have two possibilities to participate. Table 3 and Figure 3 show participation rates in each of the two stages. ${ }^{20}$

\footnotetext{
${ }^{20}$ Participation rates at stage 2 are calculated as the number of participations at this stage divided by the number of senders who abstained at stage 1 .
} 
FigURE 3A: SENDERS’ PARTICIPATION AT STAGES 1 AND 2 IN IP.

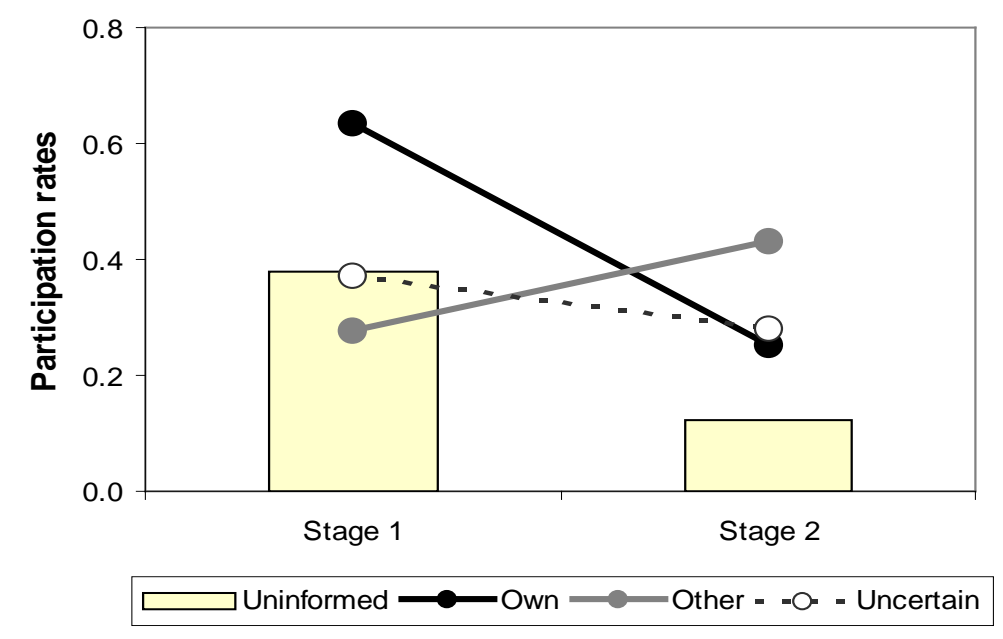

FigURE 3B: SENDERS’ PARTICIPATION AT STAGES 1 AND 2 IN IS.

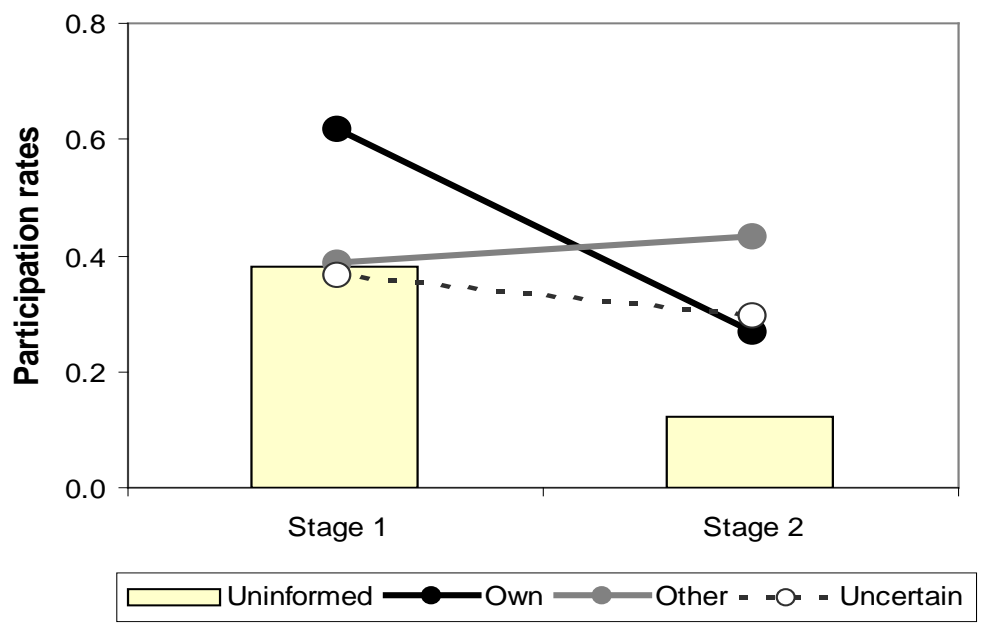

RESULT 5: Senders attempt to influence their neighbor. If the receiver is an ally, senders mainly vote at stage 1 . If the receiver is an adversary, senders participate more at stage 2.

Table 3 and Figure 3 show substantially higher participation rates for allies at stage 1 than at stage 2 in both IP (63\% vs. 25\%) and IS (62\% vs. 27\%). The difference is statistically significant (5\%-level, one-tailed Wilcoxon signed ranks test) in both cases. 
For other, we observe the opposite: senders' participation rates are lower at stage 1 than at stage 2 (28\% vs. $43 \%$ in IP; 39\% vs. 43\% in IS). The difference is significant (5\%level, one-tailed Wilcoxon signed ranks test) for IP, but not for IS (at the $10 \%$ level). In uncertain, senders participate at a higher rate at stage 1 than at stage 2 (37\% vs. 28\% in IP; $37 \%$ vs. $30 \%$ in IS), but the differences are much smaller than in own and insignificant at the $10 \%$ level.

Note that 'senders' in US have higher participation rates at stage 1 than at stage 2 (38\% vs. 12\%). This holds for all 'information conditions' in each electorate. In fact, at stage 1

they participate at the same rate as senders in other or uncertain do when information is exchanged. This appears to imply that there is a tendency to participate at a base rate of $30-40 \%$ by senders at stage 1 , unless they are matched with an ally, in which case their turnout is almost twice as high. In the absence of information, receivers participate at approximately this base rate as well. At stage 2, the 'uninformed' base rate is at approximately $10-15 \%$. In own and uncertain, senders participate at somewhat higher rates than this, but the most noticeable fact is that senders whose neighbors are adversaries vote at a much higher rate (43\%) at stage 2 , when their decision is not observed.

The participation levels of senders and their patterns of behavior are similar for partners and strangers. In this respect, neither our conjecture that participation is higher in partners nor that information exchange is more important in strangers is supported for senders. However, senders are trying to influence their receiver-neighbors. If their choices have different effects on receivers in partners than in strangers, there may be an indirect effect of senders' behavior on the role of information exchange. We will discuss this in the next subsection. Here, we close with a result for the comparative statics. The equilibrium prediction is H3, that senders' turnout rates are higher at stage 2 than at stage 1. Result 5 shows that this is rejected for allies.

\subsection{RECEIVER BEHAVIOR}

Our focus is on the response of informed receivers to their neighbor's stage 1 decision. Uninformed receivers’ behavior serves as a benchmark. We have two results. 
RESULT 6: Receivers participate at a higher rate in partners than in strangers.

Contrary to senders, receivers behave differently in partners and strangers. Their turnout is lower in the latter case (59\% vs. 52\%); both are substantially higher than the $31 \%$ in US (cf. table 3). One-tailed Wilcoxon-Mann-Whitney tests reject the null hypothesis of no differences in favor of higher rates for receivers in both informed than in uninformed (1\% significance level) and in IP than IS (10\%-level). This holds for all information conditions and for both observed decisions of their sender-neighbors (the only exception is receiver turnout after observing a vote in other). Moreover, aggregate participation by receivers is lower than by senders in IS (cf. result 4).

RESULt 7: Receivers reciprocate allied senders' stage 1 decisions in strangers.

The average participation rate in the uninformed sessions is $31 \%$ ( $c f$. table 3 ). In IP, responses to senders' stage 1 decisions vary: participation rates after observing a sender vote are equal to those after abstention in own (63\% vs. 62\%), they are lower in other (52\% vs. 59\%), and higher in uncertain (66\% vs. 53\%). Only the latter difference is statistically significant at the $10 \%$-level (one-tailed Wilcoxon signed ranks tests). In IS, we always observe higher participation rates after senders participate than when abstention is observed (own: $59 \%$ vs. $43 \%$; other: $56 \%$ vs. $51 \%$; uncertain: $58 \%$ vs. 47\%). Wilcoxon signed ranks tests reject the null of no difference for own and uncertain at the $10 \%$-level (one-tailed tests), but cannot reject it for other.

Both our conjectures for partners versus strangers are supported for receivers: participation by receivers is higher in partners and their responses to senders' choices are more systematic, i.e., information exchange is more important, in strangers. Recall that neither conjecture found support for senders. Note an important element of our design: receiver responses to sender stage 1 decisions remain unobserved by sender-neighbors, making it impossible for receivers to directly inform their neighbors about their decision. In partners, however, indirect information is passed on across rounds by way of aggregate (group) turnout(s). This allows for additional implicit coordination, which seems to outweigh local neighborhood exchange (for more, see section 4.7). As a consequence, receivers do not respond systematically to sender-neighbors' stage 1 decisions in partners. 
Finally, consider the last two comparative statics predictions of section 3. H4 predicts that receivers respond to observed abstention by participating more. This is rejected by our data, especially for the strangers treatment. H5 compares receivers' responses to an observed vote and predicts a higher turnout for receivers-adversaries. Table 3 rejects this prediction: in both IP and IS, receivers vote more after seeing an ally vote than after participation by an adversary.

\subsection{EFFICIENCY AND EARNINGS}

Efficiency can easily be measured in the NIE participation game, because groups are of equal size. In all cases the sum of revenues is the same, independent of participation and which group wins. Any participation is costly. Hence, efficiency requires that nobody participates. With our parameters, the efficient sum of earnings per round is $6 \times 4+6 \times 1=30$. The efficiency of an allocation is now simply defined as the sum of actual round earnings divided by 30. In addition, the lowest efficiency possible occurs when everyone votes. In this case, earnings are $6 \times 3+6 \times 0=18$, so the minimum efficiency is $60 \%$ in this participation game. Of course, realized efficiency is inversely related to aggregate turnout. Because of the high participation in both informed treatments, average efficiency is relatively low at $76 \%$ in IP and $77 \%$ in IS. In US it is $85 \%$. It follows directly from results 1 and 2 that the differences between informed and uninformed are statistically significant.

As for earnings, we know from result 4 that senders vote at a higher rate than receivers. Because the number of senders and receivers in the winning (and losing) groups are always equal, a direct implication is that senders earn less than receivers do. Finally, we consider the distributions of earnings for the various treatments. These are plotted in figure 4.

Figure 4 clearly shows a more dispersed distribution of earnings in IP than in IS and US. The earning distributions of IS and US are singled peaked, whereas that of IP has two peaks. Mean earnings are highest in US, because of the lower turnout. A closer inspection reveals that in partners-electorates there is typically domination by one group in terms of the number of victories (see table A-2 in appendix A). We argued before, that implicit coordination at the group level is taking place in partners. Apparently, this coor- 
FIGURE 4: EARNING DISTRIBUTION PER TREATMENT.

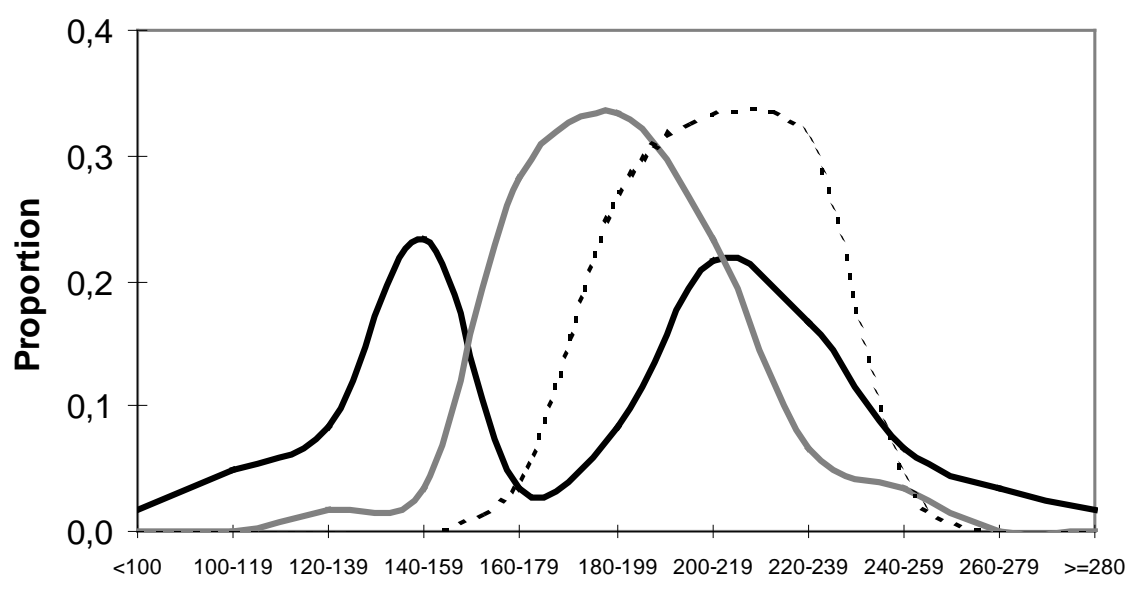

Earning categories (in tokens)

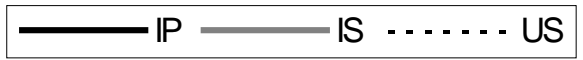

dination happens particularly within-groups, leading to situations where one group in an electorate wins more often than the other. ${ }^{21}$ Hence, the weaker group is represented by the left peak in figure 4 and the stronger group by the right peak. ${ }^{22}$

\subsection{INTERPRETING THE RESULTS}

Our collection of results appears to be quite divers. In this subsection, we try to put the pieces of the puzzle together to obtain a general picture of the effect of neighborhood information exchange on participation. We do so by formulating a conjecture of what is taking place in our experiment. Keeping in mind that what we present is indeed no more than a conjecture, we note that the processes described can account for results 1-7 and for our conclusions with respect to H1-H5. For completeness' sake, we summarize these results in table 4.

The core of our conjecture is the implicit coordination between subjects. ${ }^{23}$ This may take various forms in our experiment. A first distinction is between coordination at the neighborhood- and group-levels. A second distinction is between intra- and inter-group

\footnotetext{
${ }^{21}$ The victory rate of the weaker group is always smaller in IP than in IS, resulting in a rejection of the null hypothesis that there is no difference (one-tailed Wilcoxon-Mann-Whithney test, $1 \%$ significance level).

${ }^{22}$ Similarly, Großer et al. (2004) report higher earnings inequality across groups when groups have a mix of partners and strangers than when there are only strangers. See Lijphart (1997) for a discussion of the problems arising in democracies where turnout is unequal across groups.
} 
TABLE 4: AN OVERVIEW OF THE RESULTS

\begin{tabular}{|l|l|}
\hline \multicolumn{1}{|c|}{ Empirical results } & \multicolumn{1}{c|}{ Equilibrium comparative statics } \\
\hline R1: NIE increases turnout & H1: Turnout is higher for adversaries than for \\
R2: Partners/strangers has no overall effect & allies: rejected \\
R3: Turnout is highest in own, lowest in uncertain & H2: Allied senders vote more than receivers: \\
accepted & \\
R4: Senders participate more than receivers & H3: Senders participate at higher rates at \\
R5: Allied senders participate at higher rates at & stage 2: rejected for allies, accepted \\
stage 1; Adversary senders participate at & for adversaries \\
higher rates at stage 2 & H4: Receivers participate more after observing \\
R6: Receivers vote more in partners than in strangers & abstention: rejected \\
R7: Receivers reciprocate allied senders' stage 1 & H5: Adversary receivers participate more \\
decisions in strangers (not in partners) & after observing a vote than allied receivers: \\
& rejected \\
\hline
\end{tabular}

coordination. Within groups, coordination is to higher levels of participation, in order to 'beat' the other group. Between groups, coordination aims at reducing participation in order to decrease costs (i.e., increase efficiency). Recall that Schram and Sonnemans (1996b) and Goren and Bornstein (2000) report an increase in participation when withingroup communication is introduced. Both studies use partners. The communication allows for explicit, though not binding, coordination at the group level. In essence, their result suggests that intra-group coordination (towards participation) dominates intergroup coordination (towards abstention). We will see that the same holds for the implicit coordination through NIE in our experiment.

Introducing NIE gives neighbors the opportunity to (implicitly) coordinate in both, partners and strangers. On the other hand, (implicit) coordination at the group level can arise across rounds in partners, but not in strangers. As a consequence, we predicted the relative importance of NIE to be lower in partners than in strangers. Therefore, we distinguish between the ways in which NIE works in both treatments.

Our major finding holds for both, partners and strangers, however: NIE substantially increases overall participation. This indicates that interaction within neighborhoods has a strong effect per se. For strangers, this follows directly from a comparison between IS and US (58\% vs. 38\%; $c f$. result 1). For partners, we note that Schram and Sonnemans (1996a) report an average turnout of $42 \%$ without NIE, which is much lower than the observed 61\%-points here ( $c f$. figure 1$)$.

\footnotetext{
${ }^{23}$ We do not intend to neglect voters' individual incentives. Coordination (explicit or implicit) allows individuals to better achieve their individual goals in repeated interactions, however. Our conjecture is best seen as an attempt to provide a unified description of the behavioral patterns observed in our experiment.
} 
We first consider the implications of our conjecture for partners. Implicit intra-group coordination appears to be taking place, here. This gives rise to distinct turnout levels across groups, yielding the bimodal distribution of earnings described above. The implicit group-level coordination leads to high average levels of participation by receivers (over 59\%). Senders play an important role in determining the level at which groups coordinate ( $c f$. sections 4.3 and 4.4). When neighbors are allies, senders try to provoke high levels by high participation at stage 1 . This is partly successful, because it boosts the 'coordinated' level of turnout to almost 70\%. This is not caused by direct reciprocation by receivers, however. Even receivers who observe abstention vote at higher rates. We attribute this to them experiencing higher levels of participation in all rounds. In this way, the senders' 'signals' have an effect across rounds just as much as within rounds. It lifts the 'coordinated' turnout to a higher level. Because the implicit coordination is taking place within groups, senders only send their signals to allies (they withhold them to adversaries). This combination of partners- and NIE-effects (the latter predominantly driven by senders) can account for results 1,3 (for the own-other comparison), 4, 5, and 7 for partners. It also accounts for our confirmation of H2 and H3 (for adversaries), and for our rejection of H1, H3 (for allies), H4, and H5. Finally, note that overall (as in the studies mentioned above) no inter-group coordination to (efficient) abstention is observed.

In strangers, as argued above, implicit coordination seems impossible at the group level. Here, subjects rely much more on a period-by-period coordination in neighborhoods (when neighbors are in the same group). Once again, intra-group seems to dominate inter-group coordination. Senders signal their willingness to joint participation to allies by voting early. Contrary to partners, we see a strong response by allied receivers in strangers. They reciprocate a vote by their neighbor by voting themselves at much higher rates than after observing abstention. The situation is completely different when neighbors are adversaries. Senders no longer take the initiative to coordinate at higher participation. Receivers realize this and do not respond to the observed decision. They (rightfully) assume that observed abstention is uninformative about second stage sender behavior. The case where the neighbors' preferences are uncertain shows intermediate results. This process can account for results 1, 3 (for the own-other comparison), 4, 5, and 
7 for strangers, for our confirmation of $\mathrm{H} 2$ and $\mathrm{H} 3$ (for adversaries), and for our rejection of H1, H3 (for allies), H4, and H5.

Hence, implicit intra-group coordination at the neighborhood- and group-level for partners and only at the neighborhood-level in strangers - in both cases, with an important coordinating role by senders - explain most of our findings. They also explain why Nash equilibria predict poorly, because these do no allow for any kind of coordination. Our result 2 implies that the two types of implicit coordination yield comparable turnout rates for partners and strangers, mainly because sender behavior is the same across both treatments. Result 6 is a consequence of receivers' role in grouplevel coordination in partners. The results that remain unexplained are related to two findings: (i) senders vote at a higher rate at stage 1 than at stage 2, even without NIE. As discussed above, we can think of a number of reasons why this might be the case; (ii) the uncertainty created in our treatment uncertain decreases participation. This explains the last part of result 3, but will not be elaborated, further.

\section{ConCLUSIONS}

Many social scientists are aware that the social embeddedness matters for behavior in public goods settings in general and for voter participation in particular. Putnam et al. (1993), for example, argue that there is an important link between a society's social capital and its civilians' voter participation. Empirical support for this idea is given by Carlson (1999). This social capital or embeddedness has many dimensions, however. One important element is information about others' behavior. In this study, we have isolated this element by focusing on the exchange of information within 'neighborhoods' of two voters in an electorate. We do so by extending the traditional participation game to allow for 'neighborhood information exchange' (NIE). At a first stage, 'sender-voters' decide whether or not to participate and their receiver-neighbor observes this decision. In case they abstain, senders again decide whether or not to participate at a second stage, this time simultaneously with the receivers. Sender- and receiver-neighbors are either known to be allies or adversaries or are uncertain about each other's preferences. 
The experimental results we find for the NIE-participation game support the notion that this information matters. We find substantially higher participation when information is exchanged than is usually observed in experimental participation games. Participation is highest when neighbors are allies, suggesting a positive effect of segregation on turnout. Moreover, it appears that senders strategically use their first mover position to influence the receivers. They participate substantially more when being observed by an ally than they do at the second stage, when they are not observed. The reverse holds when neighbors are adversaries. In response, receiver-neighbors (in strangers) participate more when they observe an ally-sender participating.

Though some of the comparative statics we derived from the Nash equilibria are supported by our data (notably the higher participation by senders when their neighbor is an ally), many are not (e.g., our equilibria predict that receivers will vote less after observing an ally's vote). Overall, we find little empirical support for these equilibria. This is not surprising, given previous findings in public goods experiments in general and experimental participation games in particular. Though it is conceivable that other equilibrium notions (e.g., quantal response equilibria) might provide a better underpinning of our results, it is not the goal of this study to provide these. Our aim has been predominantly empirical and explorative. We are mainly interested in observing the effect of NIE on the participation rates of distinct types of voters. The result is unambiguous: NIE increases participation. We have conjectured about the processes that are driving this result (and the poor performance of Nash equilibrium as a predictor). Our explanation centers around (implicit) coordination between subjects, taking place at both the group and the neighborhood levels for partners and within neighborhoods for strangers. In both cases, first stage behavior by senders appears to play an important role.

All in all, this study shows how sensitive participation is to small changes in the setup of these games. In the outside-the-laboratory world, the social environment is extremely more complex than just the exchange of information between two neighbors. Therefore, it should not come as a surprise that simple games cannot explain everything. The control we have in the laboratory allows us to search for explanations, one step at a time. This is how we see our study. It explores the effect of one out of many possible aspects of the social environment. In that perspective, the effect we find is remarkably strong. 


\section{REFERENCES}

Abbink, K, Sadrieh, A., 1995. RatImage, Research Assistance Toolbox for ComputerAided Human Behavior Experiments, Discussion Paper No. B-325, University of Bonn.

Andreoni, J., 1988. Why free ride? Strategies and learning in public goods experiments, Journal of Public Economics 37, 291-304.

Banerjee, A., 1992. A simple model of herding behavior, Quarterly Journal of Economics 107, 797-817.

Bartels, L.M., 1988. Presidential primaries and the dynamics of public choice, Princeton, New Jersey: Princeton University Press.

Battaglini, M., 2004. Sequential voting with abstention, working paper, Princeton University.

Bikhchandani, S., Hirschleifer, D., Welch, I., 1992. A theory of fads, fashion, custom and cultural change as informational cascades, Journal of Political Economy 100, 992-1026.

Börgers, T., 2004. Costly voting, American Economic Review 94, 57-66.

Bornstein, G., 1992. The free-rider problem in intergroup conflicts over step-level and continous public goods, Journal of Personality and Social Psychology 62, 597-606.

Butler, D., Stokes, D., 1974. Political change in Britain: The evolution of electoral choice, New York: St. Martin’s.

Carlson, N., 1999. The rationality of political culture: Voter turnout and social capital, paper presented at the 1999 Annual Meeting of the American Political Science Association.

Cason, T., Mui, V.-L., 2003. Uncertainty and resistance to reform in laboratory participation games, working paper, Purdue University and University of Notre Dame.

Dekel, E., Piccione, M., 2000. Sequential voting procedures in symmetric binary elections, Journal of Political Economy 108, 34-55.

Downs, A., 1957. An economic theory of democracy, New York: Harper and Row Publishers.

Fey, M., 1996. Informational cascades, sequential elections, and presidential primaries, working paper, Department of Politics, Princeton University

Goeree, J.K., Großer, J., 2003. Costly voting with correlated preferences, working paper, University of Amsterdam. 
Goeree, J.K., Holt C.. An explanation of anomalous behavior in binary-choice games: entry, voting, public goods, and the volunteers' dilemma, forthcoming American Political Science Review

Goren, H., Bornstein, G., 2000. The effects of intragroup communication on intergroup cooperation in the repeated intergroup prisoner's dilemma (IPD) game, Journal of Conflict Resolution 44, 700-719.

Großer, J., Kugler, T., Schram, A., 2004. Group size uncertainty and voter participation: an experimental study, working paper, University of Amsterdam.

Hsu, L.-C., Sung, Y., 2002. Experimental evidence on voting rationality and decision framing, Taiwan Economic Review 30, 247-272.

Jackson, J.E., 1983. Election night reporting and voter turnout, American Journal of Political Science 27, 615-635.

Kuhn, H.W., 1953. Extensive games and the problem of information. In: H.W. Kuhn and A.W. Tucker (eds.), Contributions to the theory of games I, 193-216. Princeton: Princeton University Press.

Ledyard, J.O., 1984. The pure theory of large two-candidate elections, Public Choice 44, $7-41$.

Lijphart, A., 1997. Unequal participation: democracy's unresolved dilemma, American Political Science Review 91, 1-14.

Lohmann, S, 1994a. Information aggregation through costly political action, American Economic Review 84, 518-530.

Lohmann, S., 1994b. The dynamics of informational cascades. The Monday demonstrations in Leipzig, East Germany, 1989-91, World Politics 47, 42-101.

McKelvey, R.D., Ordeshook, P.C., 1985. Sequential voting with limited information, American Journal of Political Science 29, 480-512.

Morton, R.B., Williams, K.C., 1999. Information asymmetries and simultaneous versus sequential voting, American Political Science Review 93, 51-67.

Morton, R.B., Williams, K.C., 2000. Learning by voting: Sequential choices in presidential primaries and other elections. Ann Arbor, Michigan: University of Michigan Press.

Offerman, T., Sonnemans, J., Schram, A., 1996. Value orientation, expectations and voluntary contributions in public goods, Economic Journal 106, 817-845. 
Palfrey, T.R., Rosenthal, H., 1983. A strategic calculus of voting, Public Choice 41, 7-53.

Palfrey, T.R., Rosenthal, H., 1985. Voter participation and strategic uncertainty, American Political Science Review 79, 62-78.

Putnam, R., Leonardi, R., and Nanetti, R.Y., 1993. Making democracy work: Civic traditions in modern Italy, Princeton: Princeton University Press.

Ragin, C.C., 1986. The impact of Celtic nationalism on class politics in Scotland and Wales. In: S. Olzak and J. Nagel (eds.), Competitive ethnic relations, Orlando, FL: Academic Press.

Rapoport, A., 1997. Order of play in strategically equivalent games in extensive form, International Journal of Game Theory 26, 113-36.

Schram, A., 1991, Voter behavior in economic perspective, Heidelberg: Springer Verlag.

Schram, A., Sonnemans, J., 1996a. Voter turnout as a participation game: an experimental investigation, International Journal of Game Theory 25, 385-406.

Schram, A., Sonnemans, J., 1996b. Why people vote: Experimental evidence, Journal of Economic Psychology 17, 417-442.

Schram, A. and van Winden, F., 1991. Why people vote: Free riding and the production and consumption of social pressure, Journal of Economic Psychology 12, 575-620.

Siegel, S., Castellan, Jr., N.J., 1988. Nonparametric statistics for the behavioral sciences, New York: McGraw-Hill.

Takács, K., 2001. Structural embeddedness and intergroup conflict, Journal of Conflict Resolution 45, 743-769.

Takács, K., 2002. The impact of segregation on intergroup conflict: an experimental study, working paper, Institute for Advanced Study, Budapest

Tversky, A., Kahnemann, D., 1981. The framing of decisions and the psychology of choice, Science 211, 453-458.

Weber, R.A., Camerer, C.F., Knez, M., 2004. Timing and virtual observability in ultimatum bargaining and 'weak link' coordination games, Experimental Economics 7, $25-48$.

Wit, J., 1997. Herding behavior in a roll-call voting game, working paper, CREED, University of Amsterdam 


\section{APPENDICES}

\section{Appendix A:}

TABLE A-1: SEQUENCE OF INFORMATION CONDITIONS FOR ALL ROUNDS

\begin{tabular}{|c|c|c|c|c|c|c|c|c|c|}
\hline Round & Info & Round & Info & Round & Info & Round & Info & Round & Info \\
\hline 1 & 1 & 21 & $3(2)$ & 41 & 1 & 61 & $3(2)$ & 81 & 1 \\
\hline 2 & $3(1)$ & 22 & 2 & 42 & 2 & 62 & $3(1)$ & 82 & $3(1)$ \\
\hline 3 & $3(2)$ & 23 & 1 & 43 & 2 & 63 & 2 & 83 & $3(2)$ \\
\hline 4 & 2 & 24 & 1 & 44 & 1 & 64 & 2 & 84 & 2 \\
\hline 5 & $3(1)$ & 25 & 2 & 45 & $3(2)$ & 65 & $3(2)$ & 85 & 2 \\
\hline 6 & 1 & 26 & 1 & 46 & 2 & 66 & 2 & 86 & $3(1)$ \\
\hline 7 & 1 & 27 & 1 & 47 & 2 & 67 & $3(1)$ & 87 & 1 \\
\hline 8 & $3(2)$ & 28 & 2 & 48 & $3(1)$ & 68 & 2 & 88 & 2 \\
\hline 9 & 2 & 29 & 1 & 49 & 2 & 69 & 1 & 89 & $3(2)$ \\
\hline 10 & $3(1)$ & 30 & $3(1)$ & 50 & $3(2)$ & 70 & 2 & 90 & $3(1)$ \\
\hline 11 & 2 & 31 & 2 & 51 & 2 & 71 & 1 & 91 & 1 \\
\hline 12 & 1 & 32 & 1 & 52 & 1 & 72 & 2 & 92 & 2 \\
\hline 13 & $3(2)$ & 33 & 2 & 53 & 2 & 73 & 1 & 93 & 2 \\
\hline 14 & 2 & 34 & 1 & 54 & 1 & 74 & 1 & 94 & 1 \\
\hline 15 & $3(1)$ & 35 & 1 & 55 & 1 & 75 & $3(2)$ & 95 & 1 \\
\hline 16 & 1 & 36 & $3(2)$ & 56 & $3(1)$ & 76 & 2 & 96 & $3(2)$ \\
\hline 17 & 1 & 37 & 2 & 57 & 2 & 77 & $3(1)$ & 97 & $3(1)$ \\
\hline 18 & $3(2)$ & 38 & 1 & 58 & $3(2)$ & 78 & 2 & 98 & 1 \\
\hline 19 & 2 & 39 & 2 & 59 & $3(1)$ & 79 & $3(2)$ & 99 & 1 \\
\hline 20 & $3(1)$ & 40 & $3(1)$ & 60 & 1 & 80 & 1 & & \\
\hline
\end{tabular}

1 = own, 2 = other, 3(1) = uncertain with drawing 'own', and 3(2) = uncertain with drawing 'other'.

TABlE A-2: AVERAGE PARTICIPATION RATES PER ELECTORATE (AVERAGE VICTORY RATES FOR THE WEAKER GROUP / NUMBER OF TIES)

\begin{tabular}{|c|c|c|c|}
\hline \multirow{2}{*}{ Electorate } & IP & Treatment \\
\cline { 2 - 4 } & $.725(.374 / 23)$ & $.591(.485 / 22)$ & $.366(.414 / 21)$ \\
\hline 1 & $.440(.384 / 24)$ & $.517(.475 / 27)$ & $.373(.475 / 21)$ \\
\hline 2 & $.609(.343 / 20)$ & $.475(.475 / 18)$ & $.441(.495 / 19)$ \\
\hline 3 & $.729(.303 / 16)$ & $.763(.455 / 22)$ & $.348(.444 / 36)$ \\
\hline 4 & $.529(.384 / 32)$ & $.570(.475 / 19)$ & - \\
\hline 5 & \multicolumn{3}{|c}{} \\
\hline
\end{tabular}




\section{APPENDIX B: Instructions for treatment IP [IS, US]}

Welcome to our experiment on decision-making. Depending on your own choices and the choices of other participants, you may earn money today. Your earnings in the experiment are expressed in tokens. 4 tokens are worth one Guilder. At the end of the experiment your total earnings in tokens will be exchanged into Guilders and paid to you in cash. The payment will remain anonymous. No other participant will be informed about your payment.

Please remain quiet and do not communicate with other participants during the entire experiment. Raise you hand if you have any question. One of us will come to you to answer them.

\section{$\underline{\text { Rounds, 'your group' and the 'other group' }}$}

The experiment consists of 99 rounds. At the beginning of the experiment the computer program will randomly split all participants into two different populations of 12 participants. In addition, at the beginning of the experiment the computer program will randomly divide the participants in each population into two groups of 6 participants [IS and US: At the beginning of each round (...)]. The group you are part of will be referred to as your group and the group in your population which you are not part of will be called the other group. Note that you will remain in the same population $\underline{\text { and }}$ group in the whole experiment [IS and US: Note that you will remain in the same population in the whole experiment. However, in each round participants in your electorate will be reallocated to groups.]. You will not know which of the participants belongs in the other group and which to your group. You will have nothing to do with participants in the other population in this experiment. [Additionally in IS and US: No matter what round you are in, the number of participants in the other group is always 6 and the number of participants in your group is also always 6 (12 in total).]

\section{Types 'sender' and 'receiver'}

At the beginning of the experiment the computer program will randomly appoint all participants to be either sender or receiver. Each participant has the same chance of $50 \%$ to be a sender and $50 \%$ to be a receiver. However, the computer program arranges it such that each population has 6 senders and 6 receivers. You will be told whether you are a sender or a receiver at the start of the experiment. Your type sender or receiver will not change during the entire experiment. When groups are formed at the start of the experiment [IS and US: at the start of a round] the computer program will also ensure that there are exactly 3 senders and 3 receivers in each group.

The following table shows the number of senders and receivers in each group.

\begin{tabular}{|c|c|c|c|}
\hline & Number of senders & Number of receivers & Total number \\
\hline Other group & $\mathbf{3}$ & $\mathbf{3}$ & 6 \\
\hline Your group & $\mathbf{3}$ & $\mathbf{3}$ & 6 \\
\hline
\end{tabular}

Table: Senders and receivers in the other group and in your group.

Matching of senders and receivers [not for US]

At the start of each round the computer program will randomly match one sender and one receiver to each other. Hence, if you are a sender you will be connected to one receiver and if you are a receiver you will be connected to one sender. Note that couples will be rematched at the start of each round.

\section{Three situations [not for US]}

At the start of each round the computer program will randomly determine one of the following three situations (each situation has the same chance of $1 / 3$ of being chosen):

All senders and receivers who are matched with each other are from the

1. same group (the other group or your group),

2. different groups (the other group and your group), or

3. unknown groups (with a chance of $50 \%$ from the same group and with a chance of $50 \%$ from different groups). 
The chosen situation in a round applies to $\underline{\text { all }}$ participants, senders and receivers, in a population. Hence, within a round it cannot be the case that some participants in a population are in a different situation than other participants in the same population. Which of the three situations applies will be announced to you and all other participants at the start of each round.

[A summary is given of the most important points so far]

\section{Part 1 and part 2 of a round and choices}

Each round will consist of two parts: part 1 and part 2. In each round choices will have to be made. We now explain the choices, which of the participants will be asked to make choices, and when they are made.

\section{Choices part 1:}

In part 1 of each round only senders will be asked to make choices. Receivers will not make a choice yet. Each sender will face an identical choice problem. They will be asked to make one choice. Senders can choose between the following two alternatives:

- 'Choice A': no costs involved (0 tokens).

- 'Choice B': costs are 1 token.

After all senders have made a choice in part 1, each receiver will be informed about the choice, however, only about the one made by the sender connected to her or him. Only the receiver will receive information about the sender in the same couple. Beyond that, no one gets any information about choices by others. [This paragraph is not used in US; instead: This choice is private, no other participant is informed about it.]

Senders choosing choice $B$ in part 1 are not asked to make a choice in part 2 . Senders choosing choice $A$ in part 1 will be asked to make a choice in part 2 as well.

\section{Choices part 2:}

In part 2 of each round, all senders choosing $A$ in part 1 and all receivers will be asked to make choices. Each of these participants will face an identical choice problem. They will be asked to make one choice. Like in part 1 they will choose between the following two alternatives:

- 'Choice A': no costs involved (0 tokens).

- 'Choice B': costs are 1 token.

The choices in part 2 will not be announced to anyone. Hence, in part 2 receivers are not informed about the choice of the sender with whom they are connected. Note that each receiver will only get information in part 1 about the choice of the sender connected to her or him, not in part 2. Senders will never get information about the choices of others. [This paragraph is not used in US; instead: the individual choices in part 2 are not announced to anyone either.]

\section{$\underline{\text { Earnings }}$}

After all participants in part 2 have made their choices, the computer program will count the number of $B$ choices per group in both parts, part 1 and part 2, and will compare the numbers in both groups. There are 3 possible outcomes that are relevant for your revenue in the following way. You will receive the revenue irrespective of the choice you made and whether you are a sender or a receiver.

(1) The number of $B$-choices in your group exceeds the number of $B$-choices in the other group. In this case each participant in your group (inclusive yourself) will get a revenue of $\mathbf{4}$ tokens. Each participant in the other group will get 1 token.

(2) The number of $B$-choices in your group is smaller than the number of $B$-choices in the other group. In this case each participant in your group (inclusive yourself) will get a revenue of $\mathbf{1}$ token. Each participant in the other group will get 4 tokens.

(3) The number of $B$-choices in your group is equal to the number of $B$-choices in the other group. In this case the computer program will randomly determine the group in which each participant gets a revenue of $\mathbf{4}$ 
tokens (each group has the same chance of $50 \%$ of being chosen). Each participant in the group that is not chosen will get 1 token.

Your round earnings are calculated in the following way: round earnings = round revenue - round costs. Your total earnings are the sum of all of your round earnings.

The following table gives your possible round earnings:

Your possible round earnings:

\begin{tabular}{|c|c|c|c|}
\hline Your choice & $\begin{array}{c}\text { Your group has } \\
\text { more B-choices }\end{array}$ & $\begin{array}{c}\text { Your group has } \\
\text { less B-choices }\end{array}$ & $\begin{array}{c}\text { Equal number of B-choices } \\
\text { in both groups }\end{array}$ \\
\hline Choice $A$ & $\mathbf{4}$ tokens & $\mathbf{1}$ token & $\mathbf{4}$ or $\mathbf{1}$ token (50\% chance each) \\
\hline Choice $B$ & $\mathbf{3}$ tokens & $\mathbf{0}$ token & $\mathbf{3}$ or $\mathbf{0}$ token (50\% chance each) \\
\hline
\end{tabular}

\section{$\underline{\text { Computer screen }}$}

The computer screen has four main windows.

(1) The Status window shows your type sender or receiver, the actual round number, part 1 or part 2, and the total earnings up to the previous round.

(2) The Previous round window depicts the following information about the previous round:

(a) The situation, regarding the matching between sender and receiver [not for US].

(b) If you are a receiver, the choice in part 1(in the previous round) of the sender who is connected to you [not for US].

(c) The number of B-choices in your group.

(d) The number of B-choices in the other group.

(e) Your choice.

(f) Your revenue.

(g) Your costs.

(h) Your round earnings.

(3) In the Choice window you will find two buttons. Press the button "Choice $A$ " or the button "Choice $B$ " with the mouse, or press the key " $A$ " or " $B$ ". When you have chosen you will have to wait until all participants have made their choices. If you are a receiver, this window will also inform you about the choice in part 1 in the actual round of the sender you are connected to [this sentence not for US].

(4) The Result window shows the result of the actual round (both part 1 and part 2). This happens after each participant in part 2 has made a choice. Each yellow rectangle shown represents one $B$-choice of your group and each blue rectangle represents one $B$-choice of the other group. After a few seconds the result will also appear in numbers.

At the upper bound of the screen you will find a Menu bar. You can use this to access the Calculator and $\underline{\text { History }}$ functions. The calculator can be handled with the number pad at the right side of your keyboard or with the mouse buttons. The function 'history' shows all information of the last sixteen rounds as this had appeared in the window 'Previous round'. At the lower bound of your screen the Information bar is located. There you are told the actual status of the experiment.

\section{Further procedures}

Before the 99 rounds of the experiment start, we will ask you to participate in three training-rounds. You will have to answer questions in order to proceed further in these training-rounds. In the training-rounds you are not matched with other participants but with the computer program. You cannot draw conclusions about choices of other participants based on the results in the training-rounds. The training-rounds will not count for your payment.

We will now start with the three trainings-rounds. If you have any questions, please raise then your hand. One of us will come to you to answer them. 